\title{
əPreconditioning and Formation of Maud Rise Polynyas in a High-Resolution Earth System Model $\mathscr{D}$
}

\author{
PRAJVALA KURTAKOTI \\ Los Alamos National Laboratory, Los Alamos, New Mexico, and Department of \\ Oceanography, Texas A\&M University, College Station, Texas \\ MiLENA VENEZIANI \\ Los Alamos National Laboratory, Los Alamos, New Mexico \\ ACHIM STÖSSEL \\ Department of Oceanography, Texas A\&M University, College Station, Texas \\ WILBERT WEIJER \\ Los Alamos National Laboratory, Los Alamos, New Mexico
}

(Manuscript received 19 June 2018, in final form 24 September 2018)

\begin{abstract}
Open-ocean polynyas (OOPs) in the Southern Ocean are ice-free areas within the winter ice pack that are associated with deep convection, potentially contributing to the formation of Antarctic Bottom Water. To enhance the credibility of Earth system models (ESMs), their ability to simulate OOPs realistically is thus crucial. Here we investigate OOPs that emerge intermittently in a high-resolution (HR) preindustrial simulation with the Energy Exascale Earth System Model, version 0.1 (E3SMv0), an offspring of the Community Earth System Model (CESM). While low-resolution (LR) simulations with E3SMv0 show no signs of OOP formation, the preindustrial E3SMv0HR simulation produces both large Weddell Sea polynyas (WSPs) as well as small Maud Rise polynyas (MRPs). The latter are associated with a prominent seamount in the eastern Weddell Sea, and their preconditioning and formation is the focus of this study. The steep flanks of the rugged topography in this region are in E3SMv0-HR sufficiently well resolved for the impinging flow to produce pronounced Taylor caps that precondition the region for convection. Aided by an accumulation of heat in the Weddell Deep Water layer, the ultimate trigger of convection that leads to MRPs is the advection of anomalously high upper-ocean-layer salinity. The crucial difference to WSPproducing LR ESM simulations is that in E3SMv0-HR, WSPs are realistically preceded by MRPs, which in turn are a result of the flow around bathymetry being represented with unprecedented detail.
\end{abstract}

\section{Introduction}

Polynyas are large ice-free areas along a coast or in the midst of the winter sea ice pack and are found both in the north and south polar oceans (Morales Maqueda et al. 2004).

D Denotes content that is immediately available upon publication as open access.

Supplemental information related to this paper is available at the Journals Online website: https://doi.org/10.1175/JCLI-D-18-0392.s1.

Corresponding author: Prajvala Kurtakoti, prajvala@tamu.edu
Coastal polynyas, also called latent heat polynyas, form when katabatic winds blowing off Antarctica push newly formed sea ice away from the coast, thereby continuously creating an area of ice-free ocean that is subject to extreme heat loss to the atmosphere. Open-ocean polynyas (OOPs), also called sensible heat polynyas, form far from the coast amid the winter sea ice pack. They are generally observed in conjunction with deep convective overturning events in the ocean that lead to direct interaction between middepth and surface ocean waters and are also characterized by a strong positive ocean-to-atmosphere heat flux. In this study, we focus on open-ocean polynyas that occur in the Weddell Sea. We use the term Weddell Sea polynya (WSP) to describe a large open-ocean polynya in the central Weddell Sea and the 


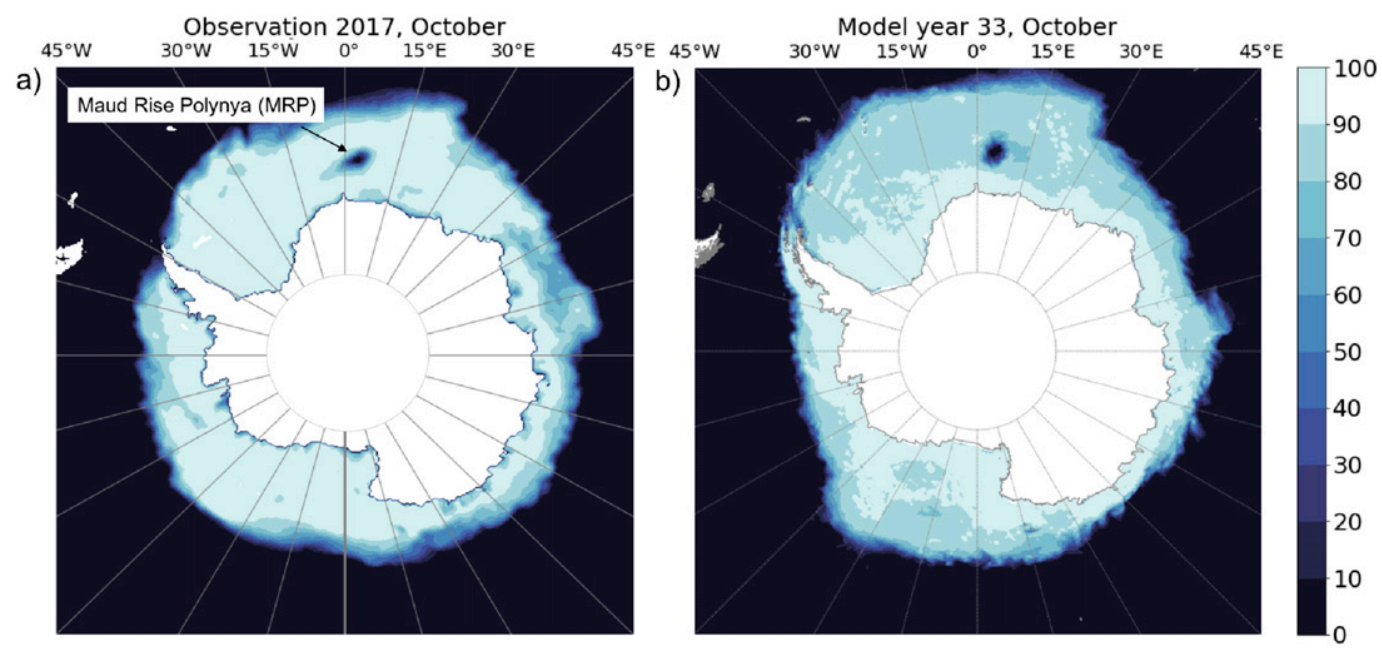

FIG. 1. (a) Satellite data (Maslanik and Stroeve 1999) and (b) simulated sea ice concentration during the month of October (observation year 2017 and model year 33, respectively) over the Southern Ocean. The shaded dark blue region is the MRP. The location of the seamount peak is at $65^{\circ} \mathrm{S}, 2.5^{\circ} \mathrm{E}$.

term Maud Rise polynya (MRP) to describe a small openocean polynya that occurs over and around the Maud Rise seamount in the eastern Weddell Sea (Gordon 1978; Martinson et al. 1981; Gordon and Huber 1990). MRPs have been observed as recently as in the austral winter of 2017 (Fig. 1a).

Physical processes in the Weddell Sea are important for the global ocean overturning circulation through their potential impact on the formation of Antarctic Bottom Water (AABW; Deacon 1963). It is therefore useful to first describe the general circulation and define the different water masses in the Weddell Sea referenced throughout this study. The Weddell Gyre is a zonally elongated cyclonic gyre that extends eastward to $30^{\circ} \mathrm{E}$ and is bound by the Antarctic coast in the south, by the Antarctic Peninsula in the west, and by the Scotia Ridge in the north (Foster and Carmack 1976; Orsi et al. 1993). A characteristic water mass of the Weddell Sea is Weddell Deep Water (WDW). It fills most of the subsurface Weddell Sea from 200 to $1500 \mathrm{~m}$ and exhibits a temperature maximum at about $500 \mathrm{~m}$, with a characteristic potential temperature between $0^{\circ}$ and $0.8^{\circ} \mathrm{C}$ and salinity between 34.64 and 34.72 psu (Foster and Carmack 1976; Gordon 1982; Gordon and Huber 1990). This water mass is fed by the Circumpolar Deep Water (CDW), which diverges from the Antarctic Circumpolar Current (ACC), flows south and then westward following the eastern limb of the Weddell Gyre, subsequently impinging on Maud Rise (Foster and Carmack 1976). Below the WDW lie two other water masses: the Weddell Sea Deep Water (WSDW) with a characteristic potential temperature between $-0.6^{\circ}$ and $0^{\circ} \mathrm{C}$ and salinity between 34.63 and 34.7 psu, and the Weddell
Sea Bottom Water (WSBW), which is denser than WSDW mainly because of potential temperatures lower than $-0.6^{\circ} \mathrm{C}$. WSBW constitutes an important component of AABW (Orsi et al. 1993). Another water mass that fills the upper $100-150 \mathrm{~m}$ in the eastern Weddell Sea is the Antarctic Surface Water (ASW; Martinson 1990).

During the austral winters of 1974-76, a large and persistent open-ocean polynya was detected in the Weddell Sea by the first operational satellite passive microwave radiometer (Zwally et al. 1983). This WSP at its biggest had an ice-free area of about $250000 \mathrm{~km}^{2}$ (Gordon et al. 2007), roughly the size of the United Kingdom. Prior to the WSP of 1974-76, MRPs were observed during part of 1973 (June and October) and 1974 (June, July, and August). The Maud Rise seamount has a diameter of about $200 \mathrm{~km}$ and extends from the surrounding deep ocean floor at 5000-m depth up to a depth of $1700 \mathrm{~m}$ at $2.5^{\circ} \mathrm{E}, 65^{\circ} \mathrm{S}$. In the winters of $1974-75$, the MRP extended westward into the central Weddell Sea, thus initiating a WSP. Deep water cooling by more than $0.4^{\circ} \mathrm{C}$ was observed in the WSP, implying deep convection that introduced cold and fresh surface winter water into WDW and WSDW in the 200-2700-m-depth range (Gordon 1981). In particular, Gordon (1981) found that the WSDW became significantly fresher and colder in the postpolynya years (1976-78) when compared to the prepolynya year (1973). This requires fullscale open-ocean deep convection and a significant transfer of heat from the ocean into the atmosphere.

Early idealized model studies investigated possible processes responsible for this deep convection. Martinson et al. (1981), for example, concluded that 
convection was initiated by static instabilities, induced by surface cooling and continuous sea ice formation with associated brine rejection. More recent studies based on numerical simulations with sea ice-ocean models revealed a more complex dynamical picture. Using a lowresolution $\left(1^{\circ}\right.$ horizontal resolution) version of such a model together with interannual atmospheric forcing, Hirabara et al. (2012) were able to simulate an open-ocean polynya in the eastern Weddell Sea. They found that common factors essential for an OOP to form are the following: 1) increased potential instability, 2) high surface salinity, and 3) a cyclonic wind stress anomaly near Maud Rise. They suggested that air-sea interactions should be simulated using fully coupled atmosphere-ice-ocean general circulation models (GCMs) to reproduce the open-ocean polynya formation processes more realistically. Such comprehensive models are nowadays mostly referred to as Earth system models (ESMs).

Cheon et al. (2015) simulated a WSP using a lowresolution version of the GFDL sea ice-ocean model forced by atmospheric reanalysis winds. They found that an anomalously strong negative wind stress curl over the Weddell Sea intensifies the cyclonic Weddell Gyre causing the warm and salty WDW to upwell, thereby triggering a WSP. Cheon et al. (2014) attributed the transition to a more negative wind stress curl to the recovery of the southern annular mode (SAM) index from a prolonged negative phase to more positive values. Furthermore, a prolonged negative phase of SAM and a strong La Niña were found to induce drier and colder surface conditions and thus more sea ice formation and brine rejection, both of which increase the sea surface salinity, potentially triggering deep convection (Gordon et al. 2007). To summarize, three main processes have been identified to precondition and sustain convection in the WSP region: 1) heat content of the WDW, which provides a heat reservoir at depth (Lindsay et al. 2008; Martin et al. 2013; Cheon et al. 2015); 2) strong negative wind stress curl over the Weddell Sea, which enhances the cyclonic Weddell Gyre causing upwelling of WDW (Cheon et al. 2015); and 3) increase in surface salinity, which destabilizes the upper ocean and increases the upward flux of WDW (Gordon 2014; de Lavergne et al. 2014).

The low-resolution model studies described above focused on WSPs since they could not fully resolve the circulation and bathymetry around the Maud Rise seamount. Yet, MRPs are observed as precursors to the WSPs in the 1970s. Therefore, separate model studies, more or less idealized but all at resolutions higher than $15 \mathrm{~km}$, have set about investigating MRP formation processes somewhat independently from those responsible for WSPs. Holland (2001) used an idealized model to show that oceanic eddies shedding at Maud Rise provide the necessary upward heat flux from the WDW to the upper mixed layer to form MRPs. He in particular demonstrated that cyclonic eddies can lead to a reduction of ice concentration at the northern flank of Maud Rise because of the associated ice-ocean stress leading to ice divergence. Other studies (Ou 1991; Alverson and Owens 1996; Beckmann et al. 2001) focused on the impact that a Taylor column forming over Maud Rise may have on localized convection around Maud Rise.

The Taylor-Proudman theorem states that in a homogeneous fluid under the condition of slow, steady, and inviscid flow, the horizontal component of velocity cannot vary with depth (Proudman 1916; Taylor 1923). In the ideal settings of a laboratory, a Taylor column appears as a stagnant cylinder recirculating over an obstacle in a rotating flow. This means that variations in bottom topography can influence oceanic flows even at the surface depending on the height of the Taylor column and on the ambient stratification. In the eastern Weddell Sea, where Maud Rise lies, the stratification is very weak, the oceanic flows are characterized by small Rossby numbers, and the flow is nearly frictionless (Alverson and Owens 1996). Under these specific conditions, the Maud Rise region can theoretically support a weak Taylor column (Hogg 1973; Chapman and Haidvogel 1992). The Maud Rise seamount rises from the surrounding sea floor by more than half of the surrounding water depth. Its "scaled bump height" (defined as the ratio of the seamount height to the surrounding ocean depth; see, e.g., Meredith et al. 2015) is well capable of influencing oceanic flow above it. Alverson and Owens (1996) looked at the effect of flow impinging on a Gaussian seamount in a stratified domain and found that it created a Taylor cap. A Taylor cap is similar to a Taylor column except that it does not necessarily form a column but instead shows a doming of water properties over the seamount, thus forming an envelope where fluid remains trapped. Prior to the formation of a steady-state Taylor cap, anticyclonic and cyclonic eddies are generated as water columns and are squeezed upstream and stretched downstream of the seamount. These eddies corotate about the seamount, until the cyclonic eddy is shed downstream, while the anticyclonic eddy remains trapped over the seamount. If the Taylor cap is tall enough to reach the surface mixed layer (or, alternatively, if the mixed layer is deep enough to tap into the Taylor cap underneath), full water column convection can be triggered. The surface mixed layer is much colder (and fresher) than the water trapped in the Taylor cap because of its exposure to the cold atmosphere. Convection over the seamount is significantly enhanced when the seamount is more 
pronounced (steeper flanks) and when stratification over the seamount is weaker (Alverson and Owens 1996). Based on the real-world parameters of bathymetry, stratification, and impinging currents around Maud Rise, this region is predestined for Taylor columns or caps to form and to prevail over extended periods of time (e.g., Meredith et al. 2015).

Only in recent years have advances in high-performance computing platforms allowed coupled climate models to perform centennial time-scale simulations with a high, ocean-eddy-resolving resolution $\left(0.1^{\circ}\right.$ or higher). A recent such study by Dufour et al. (2017) shows that the GDFL high-resolution climate model configuration with preindustrial $\mathrm{CO}_{2}$ conditions is indeed able to produce WSPs. The WSPs in these simulations were preceded by MRPs. The main focus of Dufour et al. (2017) is on the model processes and parameterizations that control the stratification in the central Weddell Sea, their impact on the accumulation of the subsurface heat reservoir (WDW), and thus on the preconditioning of WSPs.

The present study also uses a high-resolution ESM, the high-resolution Energy Exascale Earth System Model (E3SM), version 0.1 (E3SMv0-HR), baseline simulation, with the primary objective of identifying and describing the preconditioning and formation mechanisms of the simulated MRPs, in particular in view of the fact that such do not emerge in lower-resolution versions of the same model. Our motivation is twofold: 1) MRPs are seen to precede WSPs in observations as well as in highresolution model simulations. Given that the E3SMv0-HR simulation covers a large part of the rich spectrum of interactive dynamic and thermodynamic processes, our first goal is to better understand the conditions that lead up to MRPs. 2) Over the past two consecutive austral winters, sea ice observations revealed an intermittent reappearance of MRPs. The most recently observed MRP is clearly visible in the monthly mean ice concentration for October 2017 (Fig. 1a). The E3SMv0-HR simulation reproduces MRPs (Fig. 1b) that are strikingly similar to those observed.

The paper is organized as follows: The E3SM model and the E3SMv0-HR simulation are described in section 2. The model results are described and discussed in section 3. A summary and conclusions as well as an outlook on future work are presented in section 4 .

\section{Model and analysis strategy}

E3SMv0-HR is a high-resolution fully coupled ESM based on the Community Earth System Model (CESM; Hurrell et al. 2013). The atmosphere component is the Community Atmosphere Model, version 5, with the spectral element dynamical core (CAM5-SE; Dennis et al. 2012), the land component is the Community Land Model, version 4.5 (CLM4.5; Lawrence et al. 2011), the ocean component consists of the Parallel Ocean Program, version 2 (POP2) model (Smith et al. 2010), and the sea ice component is the Community Ice Code, version 4 (CICE4) model (Hunke and Lipscomb 2010). The atmosphere and land model components have a nominal $0.25^{\circ}$ horizontal resolution. The ocean and sea ice models feature a tripolar grid with a nominal $0.1^{\circ}$ horizontal resolution and 42 vertical levels (vertical resolution varies between $10 \mathrm{~m}$ at the surface and $250 \mathrm{~m}$ near the bottom). This configuration is similar to that of the high-resolution model simulation described in Small et al. (2014), except that the latter is forced with present-day atmosphere conditions, while E3SMv0$\mathrm{HR}$ is forced with fixed preindustrial atmospheric $\mathrm{CO}_{2}$ levels. Parameterizations in the ocean component of E3SMv0-HR include the $K$-profile boundary layer scheme of Large et al. (1994) to represent unresolved vertical mixing in the upper ocean and a biharmonic scheme for subgrid-scale horizontal mixing of momentum and tracers, while parameterizations for tidal mixing, dense water overflows, and (sub-)mesoscale eddy transport of tracers have been deactivated. It should be emphasized here that E3SMv0-HR was a computationally expensive, multi-institutionally designed experiment. Its specific configuration thus reflects this multiple stakeholders' community effort.

The simulation was run for 131 years, and it was initialized from year 34 of a previous E3SMv0 simulation, whose POP/CICE components were in turn initialized from a short forced simulation (which started from rest/ climatology) and whose CAM/CLM components were initialized from a standard Atmospheric Model Intercomparison Project (AMIP) run. In addition to E3SMv0$\mathrm{HR}$, we refer to a similarly configured simulation with preindustrial conditions, but with a standard $1^{\circ}$ horizontal resolution in all model components (ocean, sea ice, atmosphere and land components), hereafter referred to as E3SMv0-low resolution (LR).

E3SMv0-HR results are described in J. L. McClean et al. (2018, unpublished manuscript), which is an initialization study using an ensemble of high-resolution fully coupled transient simulations that have been initialized from different states of E3SMv0-HR and from different states of a forced POP/CICE simulation. The paper shows that the top-of-the-atmosphere energy budget in E3SMv0-HR comes into balance after simulation year 70 , oscillating about a mean value of $0.26 \mathrm{~W} \mathrm{~m}^{-2}$ (within $\pm 0.5 \mathrm{~W} \mathrm{~m}^{-2}$ ) until the end of the run. The globally averaged ocean heat content follows a similar trend, with heat mostly being stored in the upper $700 \mathrm{~m}$ during the first $70-80$ years, while later being 


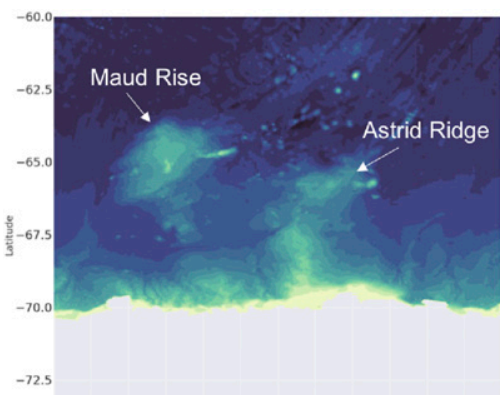

a)

$\begin{array}{llllllllllll}-75.9 .0 & -2.5 & 0.0 & 2.5 & 5.0 & 7.5 & 10.0 & 12.5 & 15.0 & 17.5 & 20.0 & 22.5\end{array}$

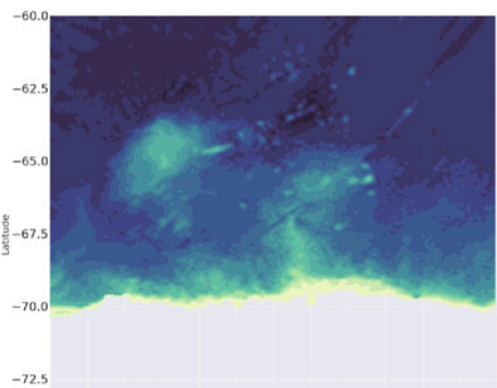

b)

$\begin{array}{lllllllllllll}-75 & \$ 9.0 & -2.5 & 0.0 & 2.5 & 5.0 & 7.5 & 10.0 & 12.5 & 15.0 & 17.5 & 20.0 & 22.5\end{array}$

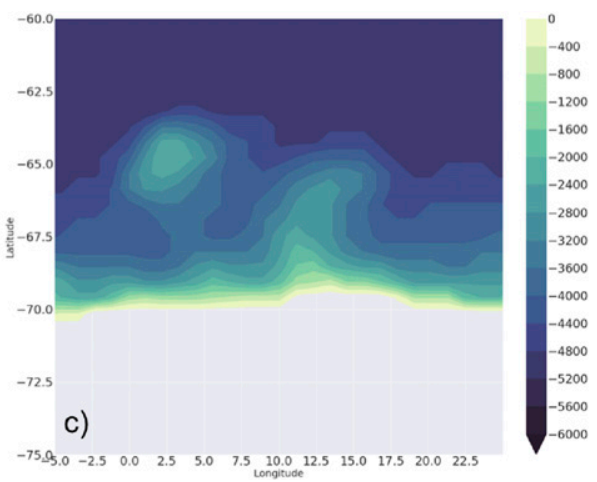

FIG. 2. Bathymetry around Maud Rise and Astrid Ridge in (a) the GEBCO observations, (b) E3SMv0-HR simulation, and (c) E3SMv0LR simulation.

redistributed at intermediate and deeper depths and reaching near equilibrium at all depths in the last 30 years of the simulation. In terms of sea ice, the simulation reproduces the Arctic ice area in winter well, but underestimates the Northern Hemisphere ice extent in summer, especially for preindustrial conditions, thus leading to an overall underrepresentation of Arctic sea ice volume. On the other hand, the seasonal cycle of Antarctic sea ice extent and volume are generally well represented. The emergence of open-ocean polynyas in the Southern Ocean encouraged us to investigate the possible reasons for their occurrence, with focus in this paper on MRPs.

Animations of monthly sea ice concentration over the entire length of the E3SMv0-HR simulation (see the online supplemental material) indicate that open-ocean polynyas form intermittently throughout the simulation, exhibiting geographical extents, timing (July-October) and locations (in the central and eastern Weddell Sea) that are very similar to satellite observations available since 1973. Only two periods, years 55-62 and 105-115, show a large ice-free embayment in the central Weddell Sea in winter. Such have not been observed since the beginning of the satellite record. In contrast, no open-ocean polynyas form in E3SMv0-LR or in any other low-resolution fully coupled CESM simulation performed in the past.

The first long-lasting (i.e., occurring for more than one winter season) MRP forms in the austral winter [JulyOctober (JASO)] of simulation year 24, reemerging sporadically and sometimes for several years in a row thereafter. The first MRP occurs east of Maud Rise (at $\sim 15^{\circ} \mathrm{E}$ ), slowly expanding westward over Maud Rise and slightly beyond during years 25 and 26, and finally becoming a small WSP in year 27. This pattern is seen before every initiation of a WSP and of an embayment, suggesting that MRPs are a precursor for WSPs, similar to what was observed in the 1970s.

In this paper, we focus on six MRP initiation events; that is, polynya events that start from a condition of no
MRP. Since MRPs seem to originate east of Maud Rise, we extend our definition of MRPs to long-lasting openocean polynyas occurring within the wider region between Astrid Ridge and Maud Rise (see bathymetry in Fig. 2a). Astrid Ridge is another prominent bathymetric feature that lies $480 \mathrm{~km}$ east of Maud Rise and extends northward from the Antarctic coast to $65^{\circ} \mathrm{S}$ (Fig. 2a; Bergh 1987). The most prominent peak on the ridge is located at $65.5^{\circ} \mathrm{S}, 12.5^{\circ} \mathrm{E}$, extending from the seafloor to $2500 \mathrm{~m}$ below the sea surface and is part of Queen Maud Land, Antarctica. Each sequence of the newly defined MRPs starts in JASO of simulation years $24,31,47,64$, 69, and 101, respectively, referred to as MRP initiation (MRP-I) years. These MRPs then continue to occur for a few years after their respective MRP-I year, but we exclude those subsequent years from the analysis of the polynya state in order to avoid any preconditioning effects on the stratification due to the presence of the polynya itself. To illustrate the mean polynya extent for each MRP-I year, Fig. 3 presents the JASO average of sea ice concentration around Maud Rise and shows the presence of a large quasi-ice-free area with mean sea ice concentration lower than $15 \%$ and mean sea ice thickness lower than $0.1 \mathrm{~m}$. To investigate the potential MRP formation mechanisms, we then study the transition from MRP-off to MRP-on conditions by analyzing a composite that consists of the years immediately preceding each MRP-I event (years 23, 30, 46, 63, 68, and 100). We refer to these years as MRP preceding (MRP-P) years. Finally, we select 17 consecutive years that show no sign of MRP or WSP formation (years 82-98), referred to as no MRP (MRP-N) years. In addition to comparing mean fields over the composites described above, we also consider anomaly fields with the purpose of better characterizing anomalous properties when transitioning from MRP-P to MRP-I and MRP-N years. The anomalies are computed with respect to a mean monthly climatology, in turn calculated over years 20-127, that is, excluding the 

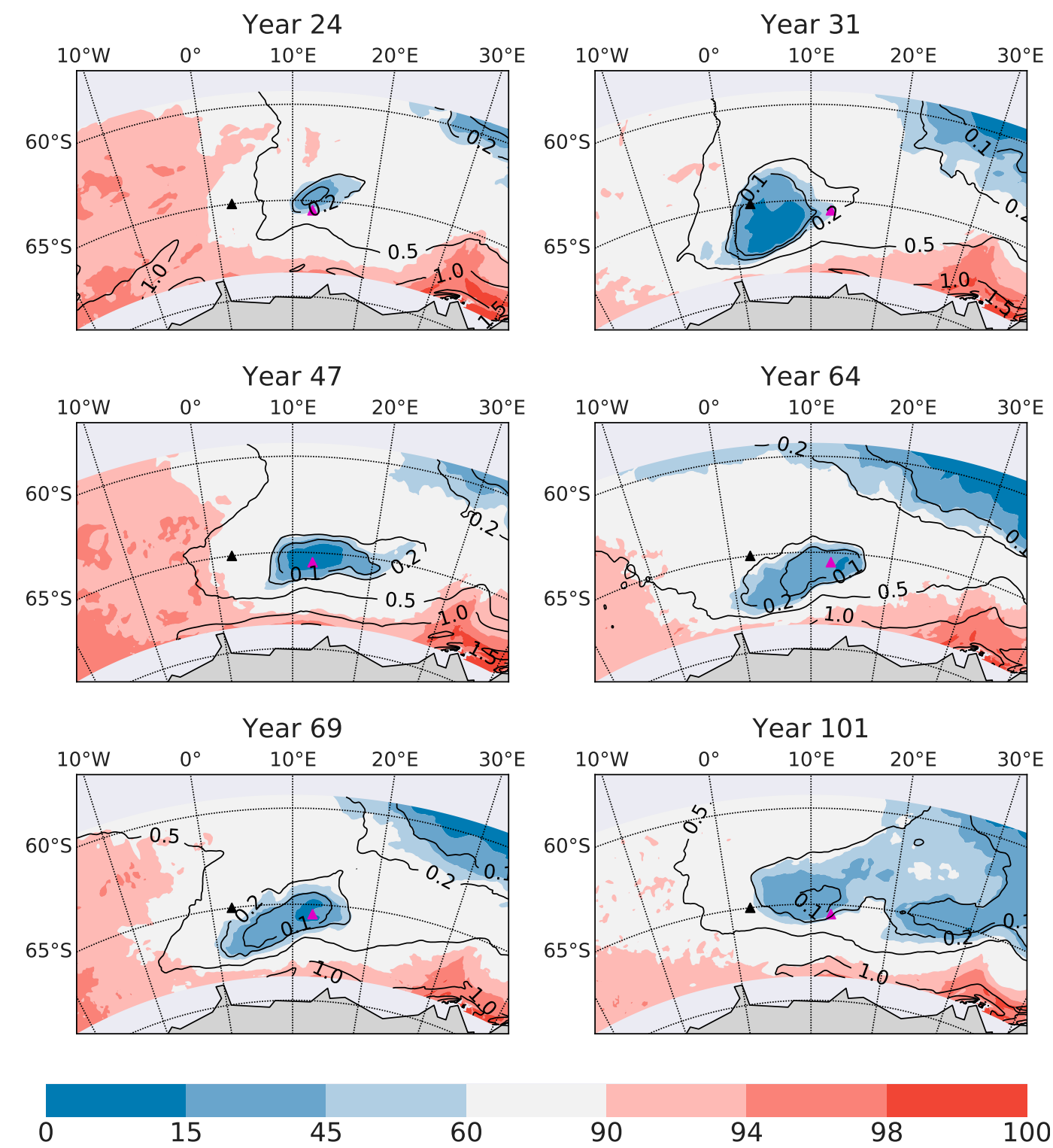

FIG. 3. Annual winter (JASO) average of sea ice concentration around Maud Rise and Astrid Ridge of the six MRP-I years in the E3SMv0-HR simulation. The contours represent sea ice thickness $(\mathrm{m})$. The shaded dark blue region is the MRP. The peaks of Maud Rise and Astrid Ridge are indicated by a black and pink triangle, respectively. Notice the nonlinear color scale.

first 20 years of the simulation when the strongest adjustments take place.

\section{Results}

The discussion of the results is organized as follows: Section 3a describes the evolution of the simulated MRPs over Maud Rise and Astrid Ridge; section 3b discusses the importance of an isolated Taylor column over Maud Rise and Astrid Ridge as a necessary precondition for deep convection; sections $3 \mathrm{c}$ and $3 \mathrm{~d}$ present two possible mechanisms that trigger the convection, the intensification of the large-scale Weddell Gyre circulation, and the formation of anomalously high-salinity waters in the upper ocean near Maud Rise; finally, section 3e describes the impact of a sequence of consecutive MRPs on deep water masses that lie below the WDW.

\section{a. Evolution of MRPs in E3SMvO-HR}

The time-space evolution of the simulated polynya events is illustrated in Fig. 4, through a Hovmöller 
a) JASO mean Maximum monthly $\operatorname{MLD}(m)$

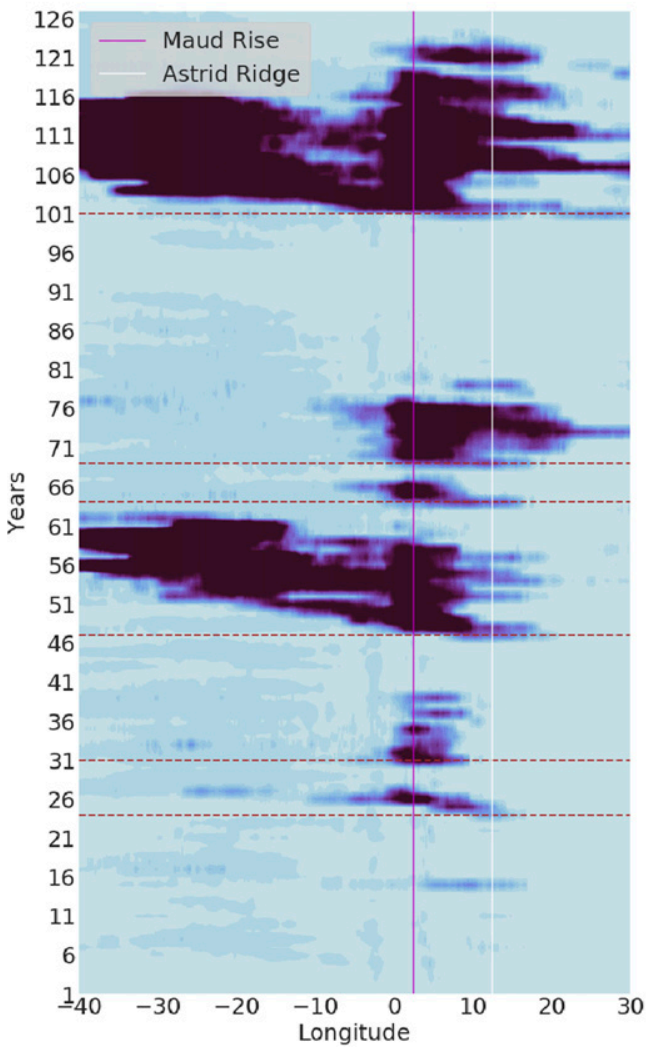

b) JASO mean Sea Ice Concentration (\%)
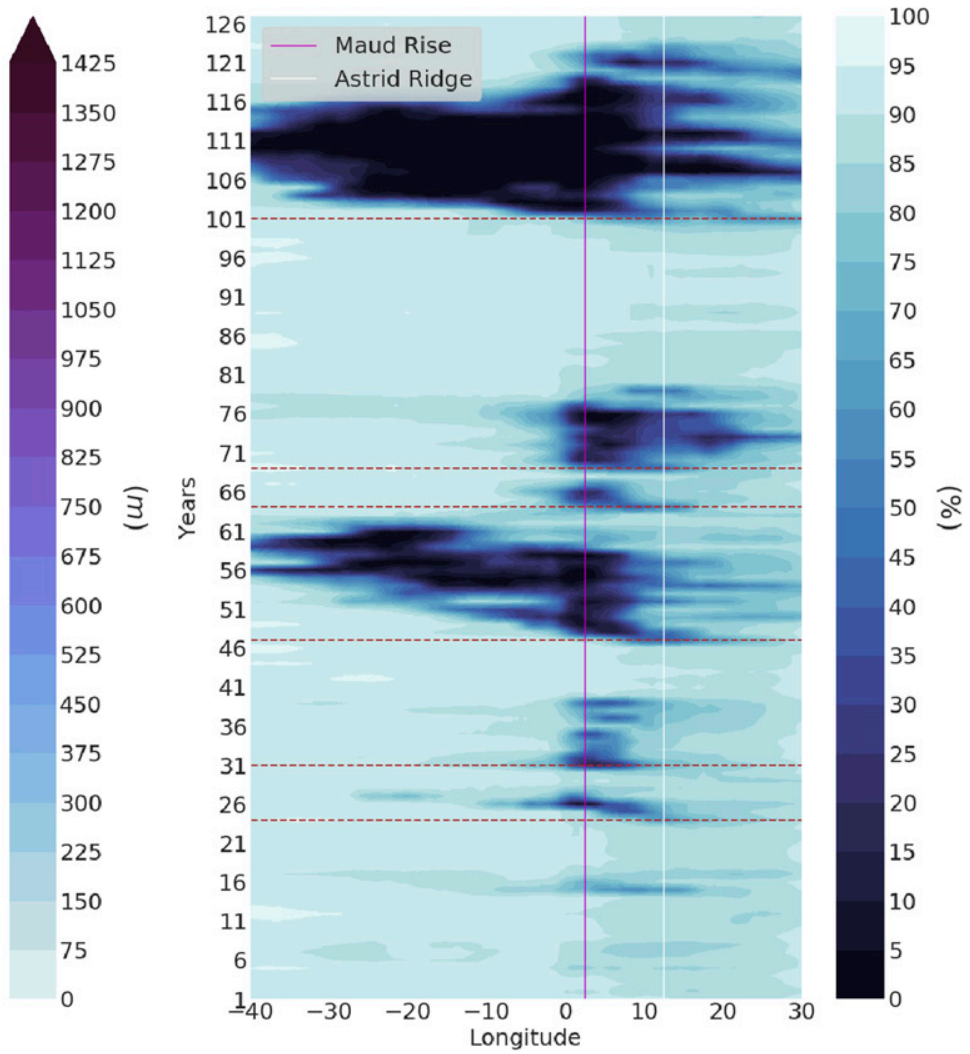

FIG. 4. Hovmöller diagram spanning the full simulation of the JASO mean (a) maximum mixed layer depth and (b) sea ice concentration averaged over the region $64^{\circ}-68^{\circ} \mathrm{S}$. The pink and white lines indicate the central peak of Maud Rise and Astrid Ridge, respectively. The horizontal red dashed lines indicate the six MRP-I years.

diagram of JASO mean maximum mixed layer depth (Fig. 4a; maximum value computed over monthly periods) and JASO mean sea ice concentration (Fig. 4b) averaged over the latitudinal band $64^{\circ}-68^{\circ} \mathrm{S}$ and spanning the entire E3SMv0-HR simulation period. The pink vertical line represents the peak of Maud Rise $\left(2.5^{\circ} \mathrm{E}\right)$, and the white vertical line represents the peak of Astrid ridge $\left(12.5^{\circ} \mathrm{E}\right)$. Deep mixed layers coincide with low sea ice concentration. Open-ocean polynyas thus reflect deep convective events. Figure $4 \mathrm{~b}$ reveals consecutive MRPs occurring over Maud Rise and between the seamount and Astrid Ridge after each MRP-I event (MRP-I years are indicated by red dashed lines in Fig. 4). We also note WSPs and large embayments occurring west of Maud Rise, with the embayments characterized by massive convective events extending to $40^{\circ} \mathrm{W}$ and beyond during two distinct time periods, years 55-62 and 105-115. Prior to WSPs, convection initiates over the Maud Rise-Astrid Ridge complex causing MRPs. The associated pattern of deep mixed layer and low ice concentration propagates slowly westward into the central Weddell Sea. The annual maximum mixed layer depth of each of the six MRP events is greater than $500 \mathrm{~m}$. This allows the core of the WDW to break into the surface layer, which leads to sea ice melting or prevents further sea ice formation.

To quantify the mean spatial extent of the simulated MRPs, and to contrast them to conditions when there are no MRPs, Fig. 5 shows the spatial distribution of the maximum mixed layer depth and sea ice concentration during September of the MRP-N and MRP-I years' composites. The typical pattern of MRPs consists of very low ice concentration (Fig. 5b) coinciding with a deep mixed layer around Maud Rise and Astrid Ridge (Fig. 5d). On the other hand, the MRP-N years' composite (Figs. 5a,c) shows mostly high sea ice concentration and low mixed layer depth, a distinct crescent of lower mixed layer depth and somewhat lower sea ice concentration encircling the northern flank of Maud Rise, and a similar but wider pattern over Astrid Ridge (note the different color scales for sea ice concentration in MRP-I vs MRP-N years). Relative to the surroundings, the reduction in sea ice concentration amounts to $\sim 5 \%$, and that of the mixed layer depth to at least $100 \mathrm{~m}$ 

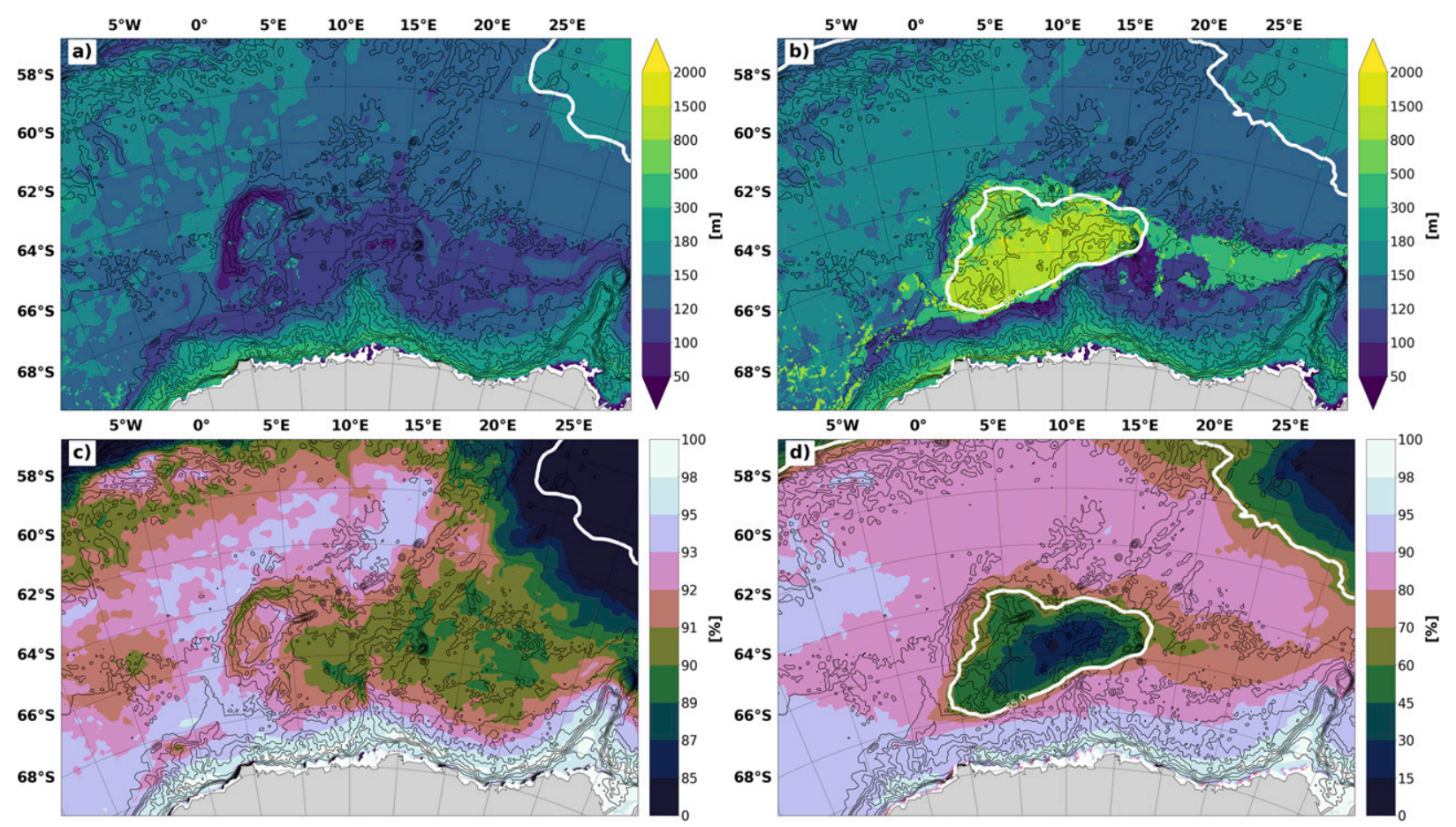

FIG. 5. September averages of (a),(b) maximum mixed layer depth and (c),(d) sea ice concentration for (left) the MRP-N composite and (right) the MRP-I composite. Note the nonlinear colorbar levels and the different ice concentration scales. Black contours indicate bathymetry, while the white contour marks the $65 \%$ ice concentration level.

in the crescent. The location of the crescent coincides with the strongest gradient in the bathymetry of Maud Rise. The mixed layer pattern and values are strikingly similar to what has been reported by de Steur et al. (2007) from measurements (their Fig. 2b), and the reduced sea ice concentration pattern is remarkably similar to the socalled ice halo that is commonly observed through satellite retrievals (Lindsay et al. 2004, 2008). The whole region east of Maud Rise and over Astrid Ridge is also characterized by a shallower mixed layer depth, which overlaps with a somewhat lower sea ice concentration pattern relative to the surrounding area.

To further contrast MRP-N to MRP-I conditions, and eventually study MRP preconditioning, it is useful to compare the typical hydrographic properties in MRP-N years (Fig. 6) with those in MRP-I years (Fig. 7). Both figures illustrate the September mean spatial distribution of potential temperature, salinity, and potential density (at surface pressure) at 5- and 300-m depth. We choose these two depths to contrast the spatial distribution of the cold surface mixed layer (ASW) with the warm subsurface layer (WDW). The simulated patterns and values of these variables are again strikingly similar to what has been observed around this region (e.g., de Steur et al. 2007). In the MRP-I composite, the surface properties around Maud Rise and Astrid Ridge (Figs. 7a,c,e) are distinctly warmer, saltier, and denser than in the corresponding MRP-N composite (Figs. 6a,c,e). Higher density, in particular, indicates considerable convective potential energy release (e.g., Stössel and Kim 2001). A striking feature is the highest density emerging on the northeast flank of the Astrid Ridge peak (Fig. 7e), which is also the region east of Maud Rise where most MRPs are initiated (Fig. 4b). At depth ( $300 \mathrm{~m}$; Figs. 7b,d,f), the water over the Maud RiseAstrid Ridge complex is colder, fresher, and denser compared to the immediate surrounding water. In fact, this surrounding water is characterized by a crescent of anomalously warm and salty water that reflects the infiltration of WDW seemingly propagating along the northern flank of the Maud Rise-Astrid Ridge complex.

\section{b. Local topographic effects of Maud Rise and Astrid Ridge on preconditioning: Role of the Taylor cap}

We next investigate possible local mechanisms that precondition the Maud Rise region for deep convection and MRP formation. The most striking feature in Figs. 6b, 6d, and $6 \mathrm{f}$ is the halo of high temperature and high salinity at depth around the Maud Rise-Astrid Ridge complex, which is similar to but more pronounced than what is seen in MRP-I years (Figs. 7b,d,f). Even at the surface, the MRP-N composite shows the presence of a crescent-shaped region of higher temperature along the northwestern flank of Maud Rise (with a similar but 

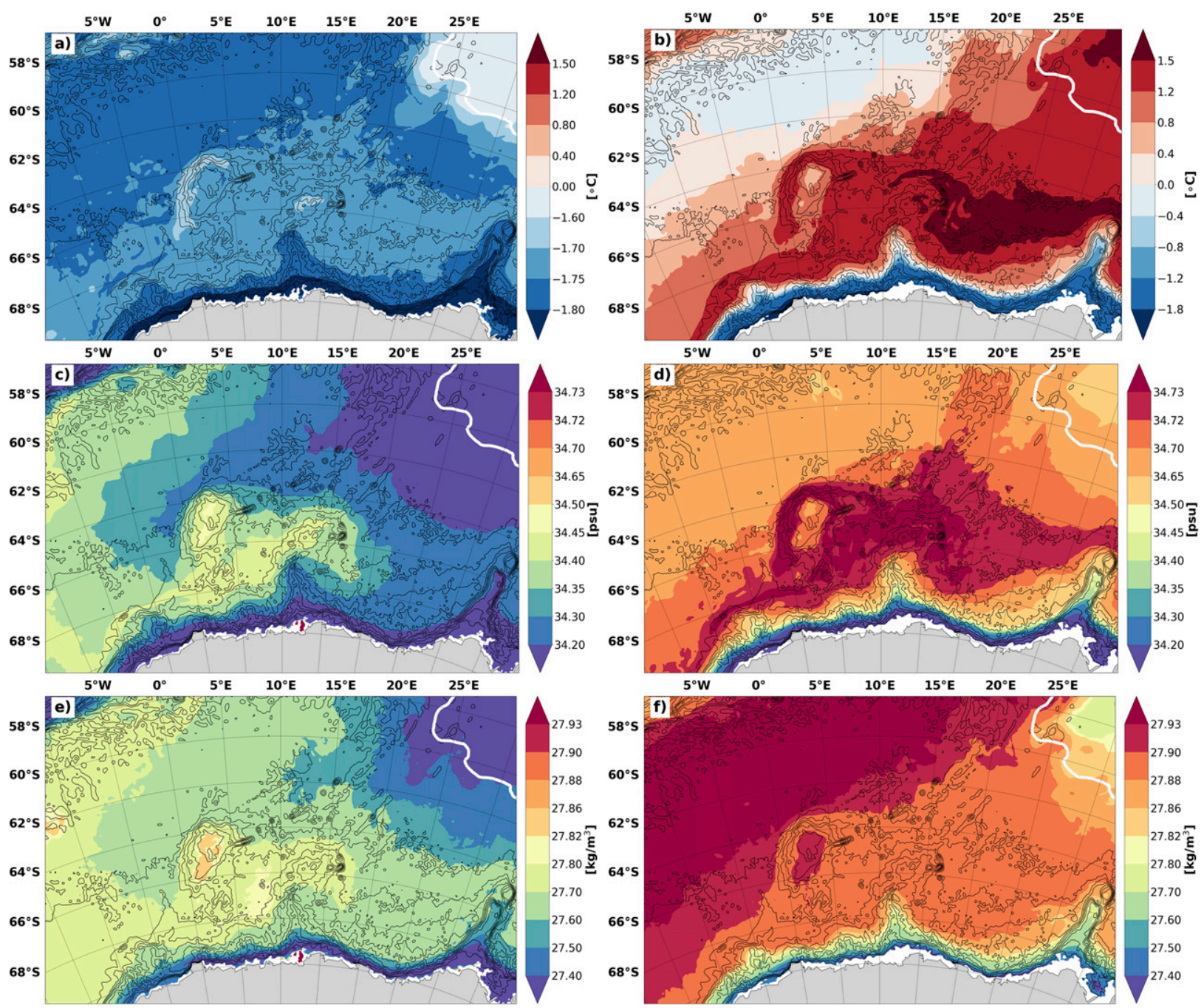

FIG. 6. September averages of (a),(b) potential temperature; (c),(d), salinity; and (e),(f) potential density (with respect to the surface), for the MRP-N composite at (left) 5-m and (right) 300-m depth. Note the different colorbar levels for (a) and (b) and the nonlinear colorbar levels for salinity and potential density. The white contour marks the $65 \%$ ice concentration level.

smaller crescent near the peak of Astrid Ridge), a clearly higher salinity pattern over Maud Rise-Astrid Ridge, and a corresponding pattern of denser water (Figs. 6a,c,e). These features point to the presence of a Taylor cap, with the strongest indication for such over Maud Rise. The stronger cap is supported theoretically by the fact that Maud Rise features a significantly larger scaled bump height than Astrid Ridge, in agreement with Meredith et al. (2015, their Fig. 10). The flow field of the Weddell Gyre makes it impinge on Maud Rise and Astrid Ridge from the east. This is indicated by the path of warm and salty WDW at 300-m depth. The Taylor cap prevents the impinging flow from going over the seamount even at the surface. As a result, the impinging flow must go around the obstacle, in this case Maud Rise and to some extent Astrid Ridge. This causes the subsurface WDW to entrain into the surface layer along the steep bathymetric slopes, creating the slightly elevated temperature signal at the surface. The water mass over Maud Rise having a distinctly different temperature and salinity signature than the surrounding waters points to the presence of a body of water that remains fairly isolated over the seamount, that is, a persistent Taylor cap, even in MRP-N years. The Taylor cap is thus a crucial preconditioning for MRPs to form at that location, as pointed out in earlier studies (see section 1).

The Taylor cap over Maud Rise can accordingly be distinguished by water that is cold and fresh relative to its immediate surroundings at depth, that is, a water mass that is isolated from the impinging WDW. The evolution of this feature in time and space over the 

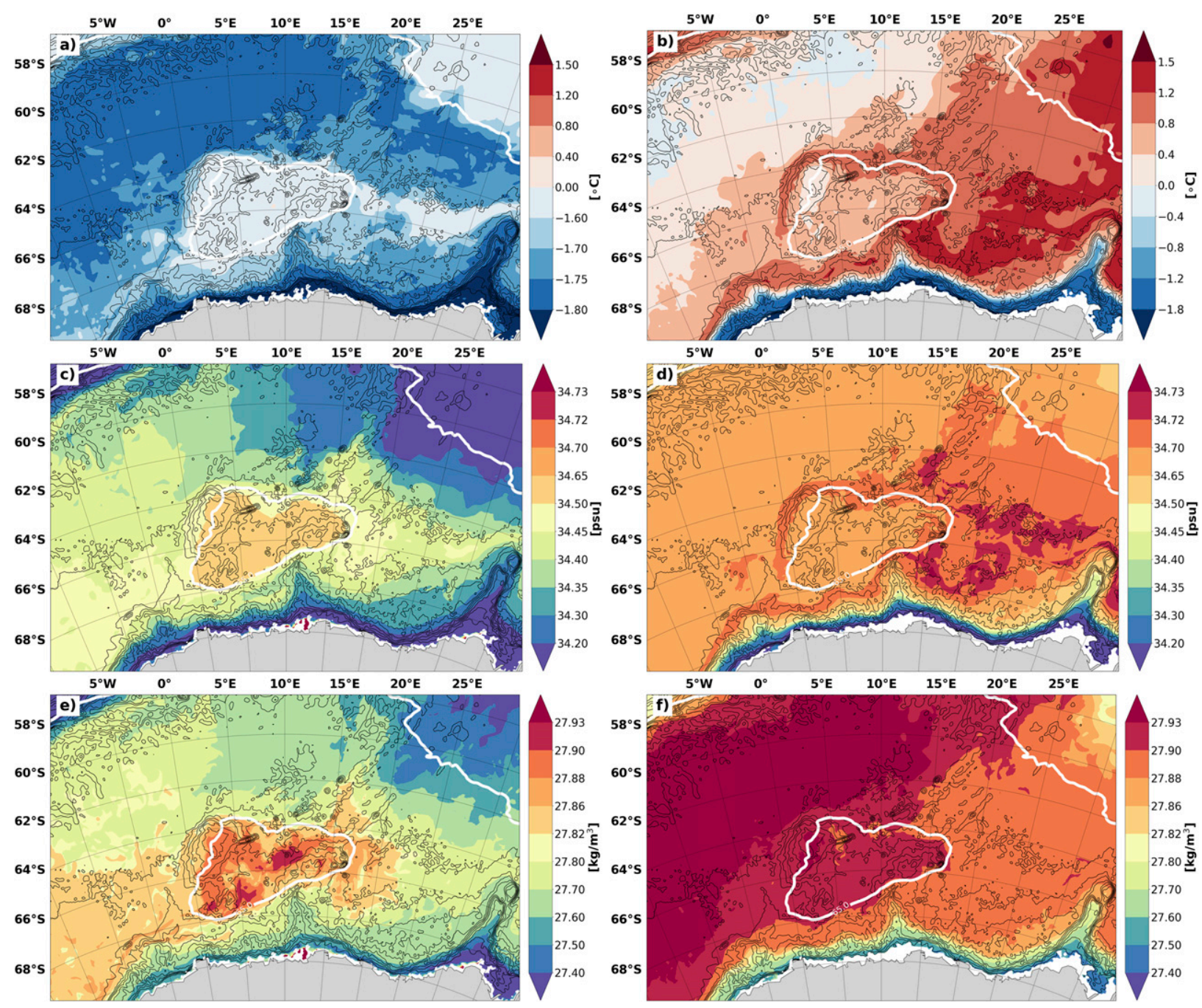

FIG. 7. As in Fig. 6, but for the MRP-I composite.

entire period of the E3SMv0-HR simulation is illustrated in Fig. 8, which presents the Hovmöller diagram of the temperature and salinity field averaged over the 2501000-m-depth range (i.e., below the pycnocline) and over the latitudinal band $64^{\circ}-68^{\circ} \mathrm{S}$. The Taylor cap over Maud Rise can readily be identified by the relatively colder and fresher subsurface water over the seamount with respect to its immediate surrounding (WDW). Such a feature is always present: Even during the MRP-N years 91-101, when the subsurface water over MR is warmer and saltier than in other years, it is still colder and fresher than the surrounding WDW. It is also apparent that a weaker Taylor cap tends to linger over Astrid Ridge, although not as persistently as over Maud Rise. Finally, Fig. 8 shows that low-temperature and low-salinity episodes are also present east of Astrid Ridge, propagating westward, and getting enhanced over the peak of Astrid Ridge, and even more so over Maud Rise.
It is important to describe the flow field around Maud Rise, which is illustrated in Fig. 9 in terms of vorticity of the sea ice drift (Fig. 9a), and a meridional section across the peak of Maud Rise (which is protruding into the bottom part of the section) of zonal currents overlapped by contours of isopycnals (Fig. 9b). Both panels reflect conditions for September of the MRP-I years' composite. The strong positive vorticity (red) along the northwestern flank of Maud Rise highlights anticyclonic flow that emerges as the impinging flow goes around the seamount. The currents that create this vorticity pattern are clearly visible at the north side of the section (Fig. 9b), with blue shading meaning westward currents and red shading indicating eastward currents. Both currents are seemingly a baroclinic feature as indicated by the opposite sloping isopycnals north of the seamount. The crescent of positive ice vorticity emerges also in MRP-N years (not shown). 
Temperature $\left({ }^{\circ} \mathrm{C}\right)$ - WDW

a)

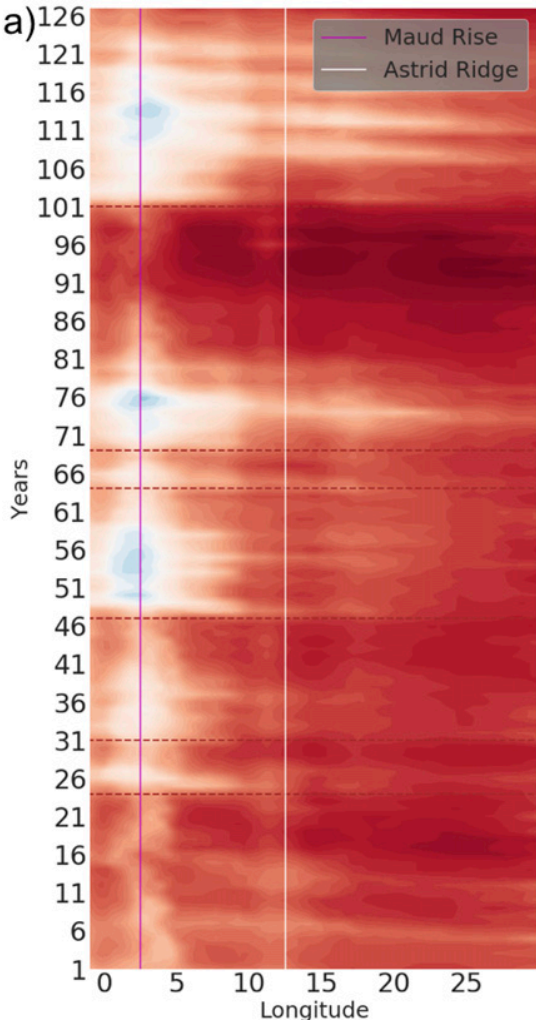

Salinity (psu) - WDW

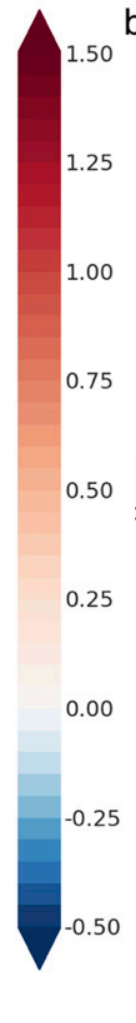

b)

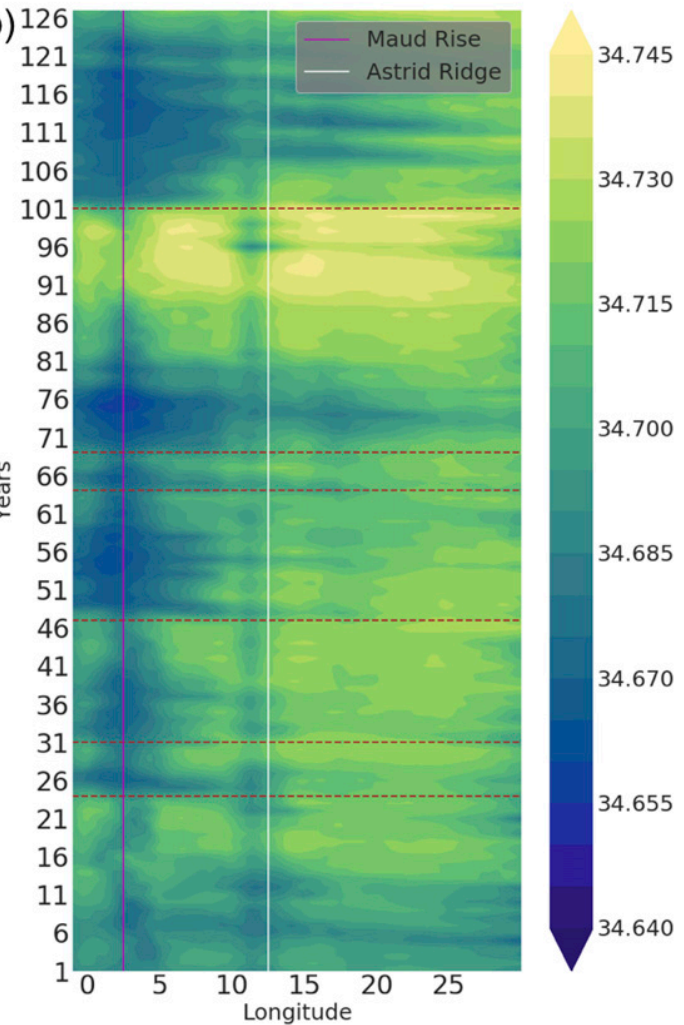

FIG. 8. Hovmöller diagram of 1-yr running averaged (a) temperature and (b) salinity averaged over 250-1000-m depth and over the region $64^{\circ}-68^{\circ} \mathrm{S}$. The pink and white lines indicate the central peak of Maud Rise and Astrid Ridge, respectively. The horizontal red dashed lines indicate the MRP-I years.

Over the peak of Maud Rise, the sea ice vorticity is negative (blue shaded region in Fig. 9a), indicating weak cyclonic flow. The presence of this cyclonic circulation is contrary to many theoretical studies that look at slow flows impinging on a seamount, using idealized model configurations (Chapman and Haidvogel 1992; Alverson and Owens 1996). These studies show that first the squashing and then the stretching of the water column resulting from the flow interacting with a seamount causes first anticyclonic and then cyclonic vorticity. Alverson and Owens (1996) show that if the impinging flow is strong enough, then the cyclonic anomaly is advected away and the anticyclonic anomaly remains over the seamount. Our results, indicating an inner circulation of opposite sign over Maud Rise, are more consistent with a theoretical study conducted using laboratory experiments (Mory et al. 1987), in which a baroclinic cyclonic eddy is generated over a Taylor column. There is also evidence of a cyclonic inner flow in observations. For example, a weak cyclonic flow over Maud Rise has been reported by Gordon and Huber (1990, their section 6.1), and, while not explicitly mentioned, sampled at hydrographic stations over Maud Rise (de Steur et al. 2007, their Fig. 4; Bersch et al. 1992). Furthermore, our simulated ice vorticity structure (Fig. 9a) is remarkably similar to the results reported in Lindsay et al. (2008, their Fig. 2) based on satellite data analyzed for a year with no MRPs. The pattern of large positive ice vorticity along the northern flank of Maud Rise emerges in concert with the similarly shaped halo of lower sea ice concentration shown in Fig. 5c, a feature that has also been reported by Lindsay et al. (2008) and discussed in Holland (2001).

To further investigate preconditioning mechanisms for MRPs, we consider the different hydrographic properties around Maud Rise between MRP-N and MRP-I years in May, which is the last month still unaffected by convection during an MRP-I year. Figure 10 shows the temperature and salinity profiles for the two composites along the same section as in Fig. 9b. MRP-I years show a more prominent Taylor cap over Maud Rise than in MRP-N years. This is indicated by a more pronounced doming of the isopycnals over the seamount, which forces the warm and salty WDW to flow more tightly around the seamount, and by a more homogenous temperature and salinity distribution below $150 \mathrm{~m}$ over Maud Rise. The density distribution described above is consistent with 

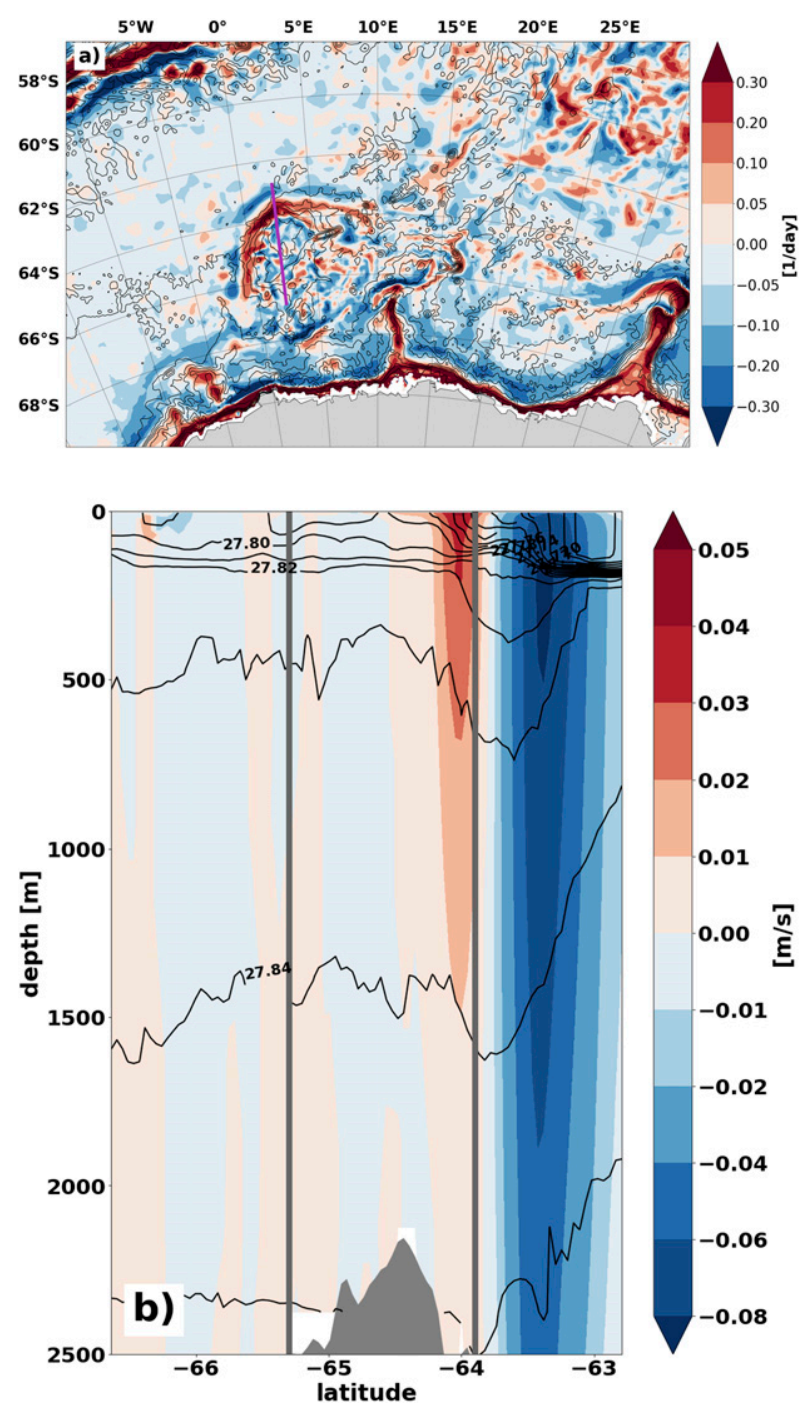

FIG. 9. September mean (a) sea ice vorticity and (b) meridional cross section at $2.3^{\circ} \mathrm{E}$ (Maud Rise) of zonal velocity (positive eastward) for the MRP-I composite. In (a), the pink line indicates the position of the cross section plotted in (b). In (b), potential density contours are in black, while the two gray vertical lines indicate the Maud Rise extent (peak at $64.5^{\circ} \mathrm{S}$ ).

observational studies. For example, de Steur et al. (2007) report doming of the isopycnal $\sigma_{0}=27.82$ between their stations 15 and 17, directly over Maud Rise (their Fig. 3a).

Above $150 \mathrm{~m}$, there is a sharp thermo- and halocline marking the transition to substantially colder and fresher water in the upper ocean. This is true for both MRP-N and MRP-I years, but the MRP-I composite indicates a lower upper-ocean stratification (Figs. 10b,d) compared to the MRP-N composite (Figs. 10a,c). In other words, there is a clear indication that, while an MRP has not been triggered yet at this stage (May), the upper $100 \mathrm{~m}$ is already saltier (and the subsurface somewhat fresher) in the early stage of MRP-I years compared to MRP-N years. The importance of the upper-ocean stratification in triggering MRPs will be further discussed in section 3d.

To summarize, we propose the following local preconditioning mechanism over the Maud Rise-Astrid Ridge complex: The existence of a persistent Taylor cap maintains low stratification over the seamount, making it a preferred location for deep convection if the cap becomes intense enough to interact with the mixed layer above it [see Alverson and Owens (1996) for the role of stratification in effecting the Taylor cap strength]. During MRP-N years, the Taylor cap remains well below the mixed layer (Figs. 10a,c), only causing a reduction in sea ice concentration or the so-called ice halo at its rim (Fig. 5a). By the fall of MRP-I years, the Taylor cap is strong enough to penetrate the mixed layer, leading to deep convection. In the next two sections, we explore large-scale as well as local effects that can trigger convection over the preconditioned region.

\section{c. Large-scale effects on Maud Rise convection: Role of the Weddell Gyre strength}

A strengthening or a southward shift of the Southern Hemisphere westerlies creates a stronger negative wind stress curl over the Weddell Sea. This strengthens the cyclonic Weddell Gyre and causes WDW to upwell in its center because of Ekman pumping. The associated doming of isopycnals can in turn trigger WSPs. While this is the way WSPs emerge in low-resolution models (e.g., Hirabara et al. 2012; Martin et al. 2013; Cheon et al. 2014), WSPs are in reality and in the E3SMv0-HR simulation preceded by MRPs.

To investigate the possible role of the wind stress in initiating MRPs, we first show the full time series of the wind stress curl anomaly (Fig. 11). Periods when MRPs, WSPs, and embayments occur are indicated by different color shading. Anomalously negative wind stress curl is needed to cause a spinup of the Weddell Gyre and an increased uptake of WDW by the gyre. The following results can be summarized from Fig. 11:1) Years when no polynyas are present generally coincide with a positive wind stress curl anomaly. 2) Large WSPs and embayments (blue and purple shading), on the other hand, typically coincide with a negative wind stress curl anomaly. The longer the anomaly stays negative, the higher the likelihood that the WSPs turn into embayments (cf. first WSP in year 26 with the transition from WSP to embayments in years 49-59 and 102-112). 3) In all MRP cases (dark gray shading) except for the first one (year 24), the wind stress curl anomaly changes from a positive to a negative state during the MRP-P year or during the first part of the MRP-I year, suggesting that the intensification of the gyre plays a role in the MRP formation. Nevertheless, a negative wind stress curl anomaly is not a 

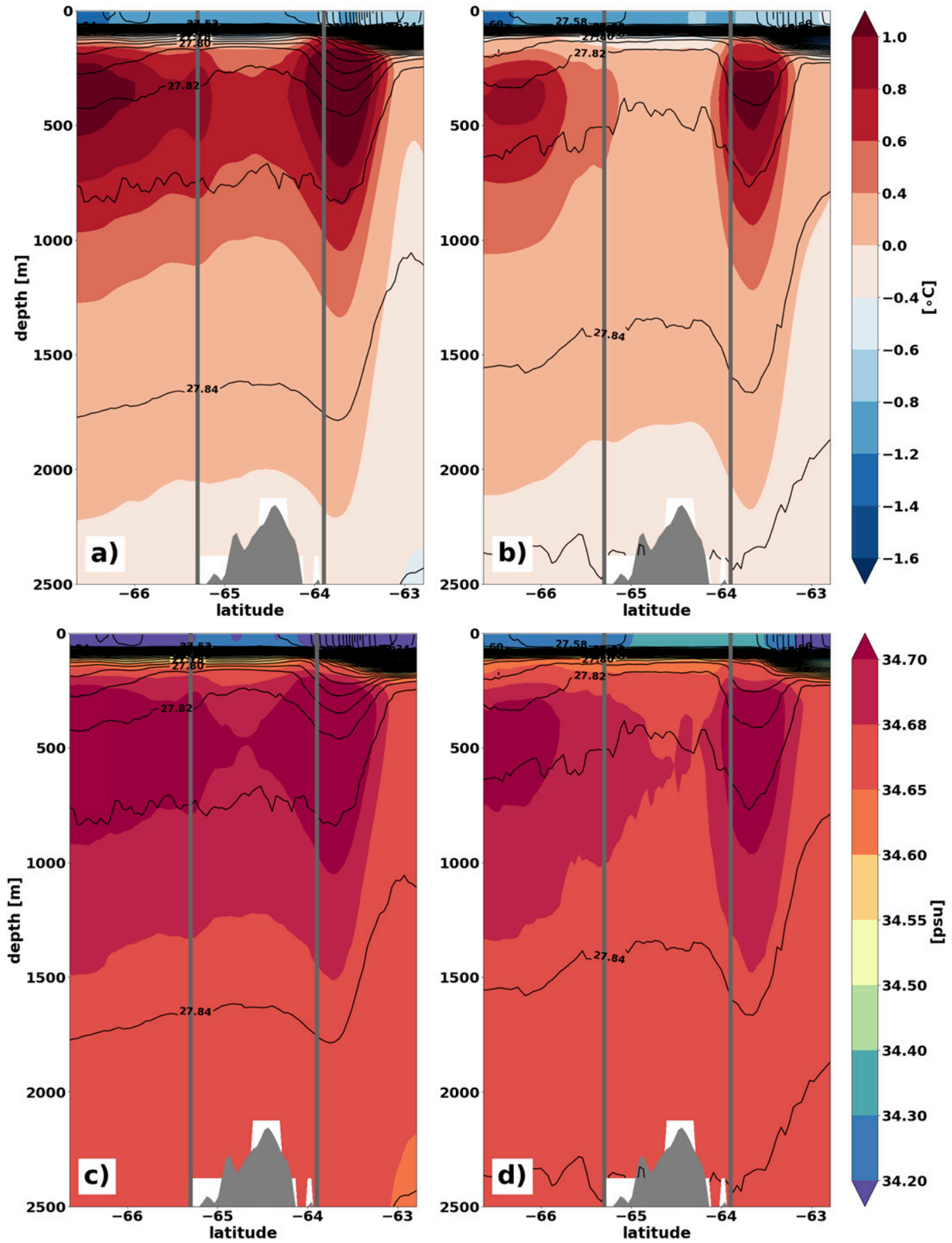

FIG. 10. Meridional cross section at $2.3^{\circ} \mathrm{E}$ of (a),(b) potential temperature and (c),(d) salinity during the month of May for (left) the MRP-N composite and (right) the MRP-I composite. Potential density contours are indicated in black. Note the nonlinear colorbar levels.

sufficient factor in triggering MRPs (and possibly WSPs as well), as there are two negative anomaly events during the MRP-N years and yet no open-ocean polynya is formed in those periods.

The spin up of the Weddell Gyre can be quantified by the barotropic streamfunction of ocean currents in the
Weddell Sea. In most of the MRP-I years, there is a slight increase in the barotropic streamfunction values over Maud Rise, Astrid Ridge, and most of the Weddell Sea that would indicate a spinup of the Weddell Gyre during the MRP-I years when compared to the MRP-P years (not shown). However, there are also MRP-I years 


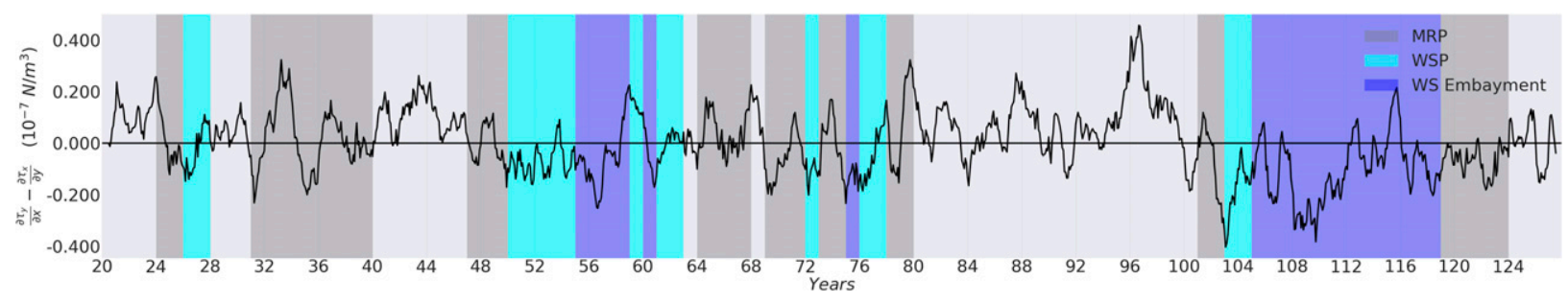

FIG. 11. Time series of the wind stress curl anomaly over the Weddell Sea (anomalies are computed with respect to a climatological monthly mean over years 20-127). The shading represents years with the different types of OOPs.

when this relationship does not hold. We therefore conclude that while the spinup of the gyre may be necessary to create a WSP, it is not a necessary prerequisite for MRPs to occur. We will investigate the relationship between the intensification of the gyre and the formation of WSPs and embayments more closely in a subsequent paper.

\section{d. Role of surface salinity in triggering MRPs}

Figure 12 shows Hovmöller diagrams of monthly temperature, salinity, and potential density anomalies averaged over the upper $100 \mathrm{~m}$ and over the latitudinal band $64^{\circ}-68^{\circ} \mathrm{S}$. The time axis (ordinate) is discontinuous in order to zoom in and focus on the transition from an MRP-P year to a MRP-I year separately for all six MRP-I cases individually. Also, the longitudinal extent of deep convection is indicated by a black box in all panels. As can be readily seen, the anomaly patterns of the six cases differ considerably. Nevertheless, the following common features can be identified: 1) The longitudinal extent of the MRPs themselves and their initiation are indicated by an abrupt switch to warm temperature anomalies in winter of the respective MRP-I year (black box in Fig. 12a). This is caused by convection (see also Fig. 4a), which entrains WDW into the upper ocean. The temperature anomaly pattern largely coincides with the salinity and density anomaly pattern (Figs. 12b,c). Note how density follows mostly the evolution of salinity. 2) There is a clear westward propagation of high-salinity anomalies starting early in the MRP-P years in all six MRP cases (black arrows in Fig. 12b). This propagation is initiated well east of Astrid Ridge.

Another feature emerging from Fig. 12 is that, except for the MRP triggered in year 31, all MRPs start forming east of Maud Rise. The reason for this seems to be the a) Temperature anomalies upper $100 \mathrm{~m}\left({ }^{\circ} \mathrm{C}\right)$ b) Salinity anomalies upper $100 \mathrm{~m}(\mathrm{psu})$

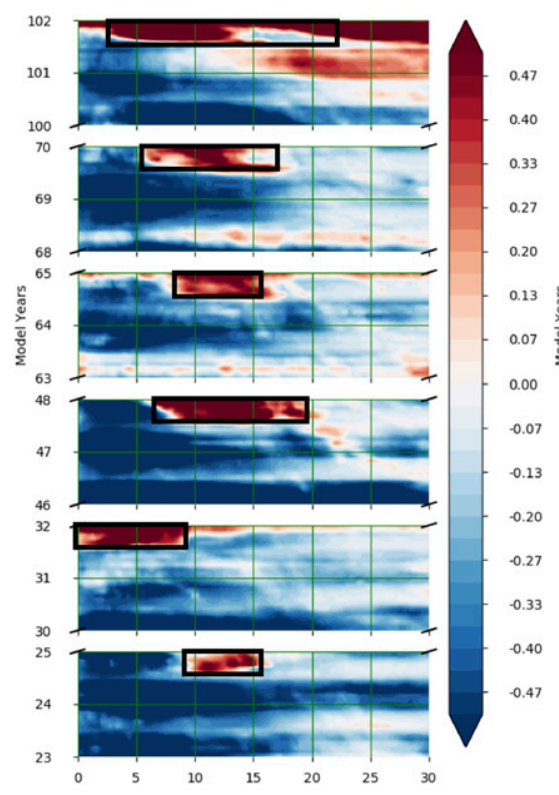

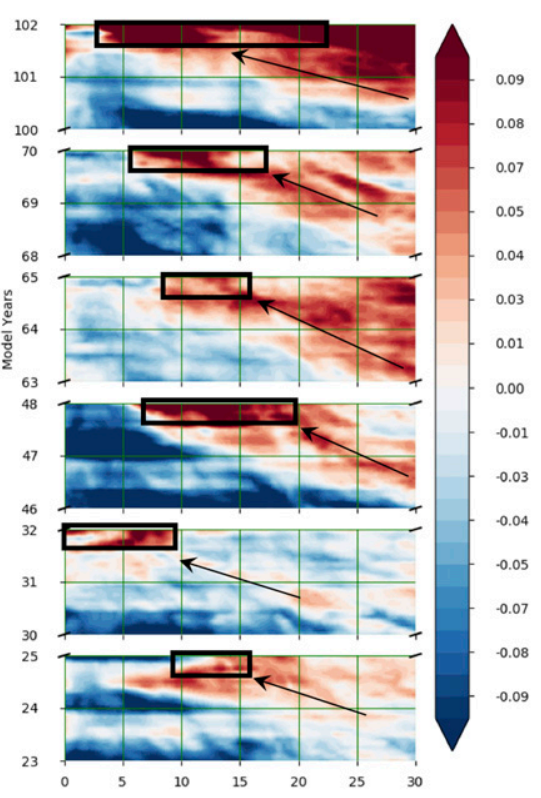

c) Density anomalies upper $100 \mathrm{~m}\left(\mathrm{kgm}^{-3}\right)$

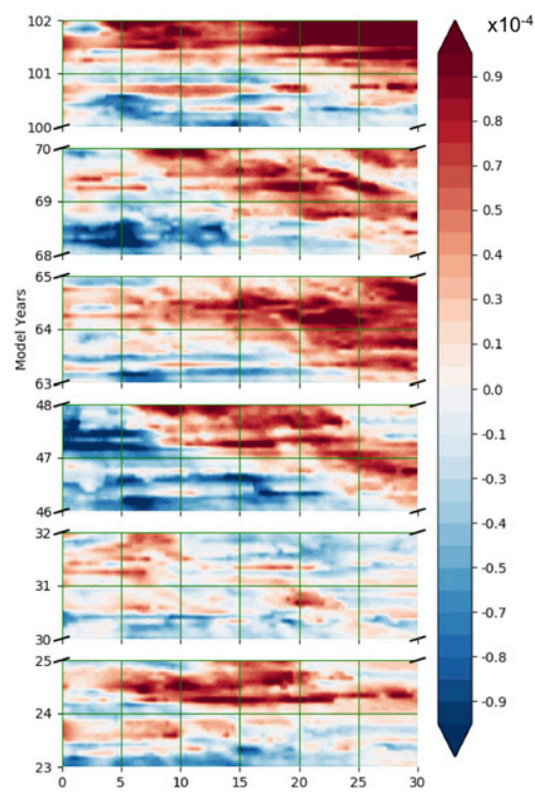

FIG. 12. Hovmöller diagrams of (a) potential temperature, (b) salinity, and (c) potential density anomalies averaged over the upper $100 \mathrm{~m}$ of the water column and over the region $64^{\circ}-68^{\circ} \mathrm{S}$. The black contoured boxes indicate the location of convection in association with the individual MRPs, and the arrows in (b) show the propagation of the salinity anomalies from east of Astrid Ridge to the Maud RiseAstrid Ridge complex. The anomalies are computed relative to the mean monthly climatology over years 20-127. 
a) Temperature anomalies upper $100 \mathrm{~m}\left({ }^{\circ} \mathrm{C}\right)$
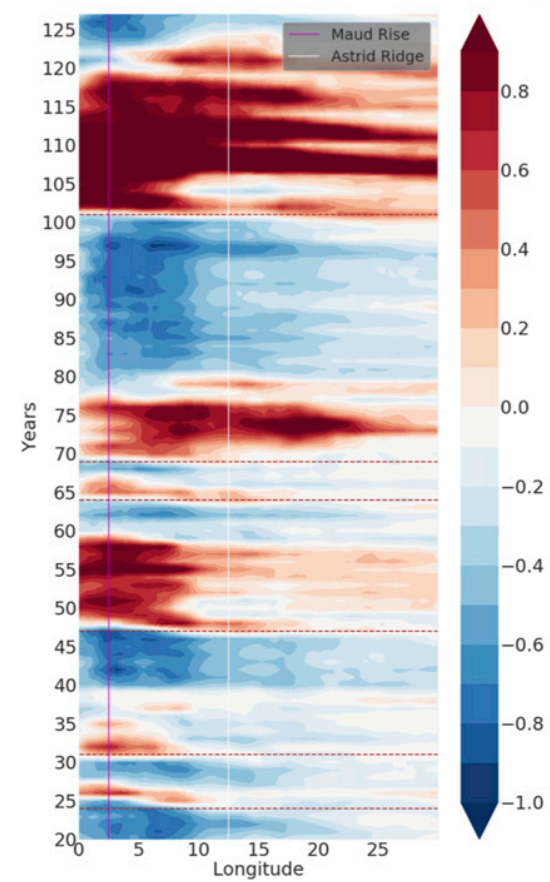
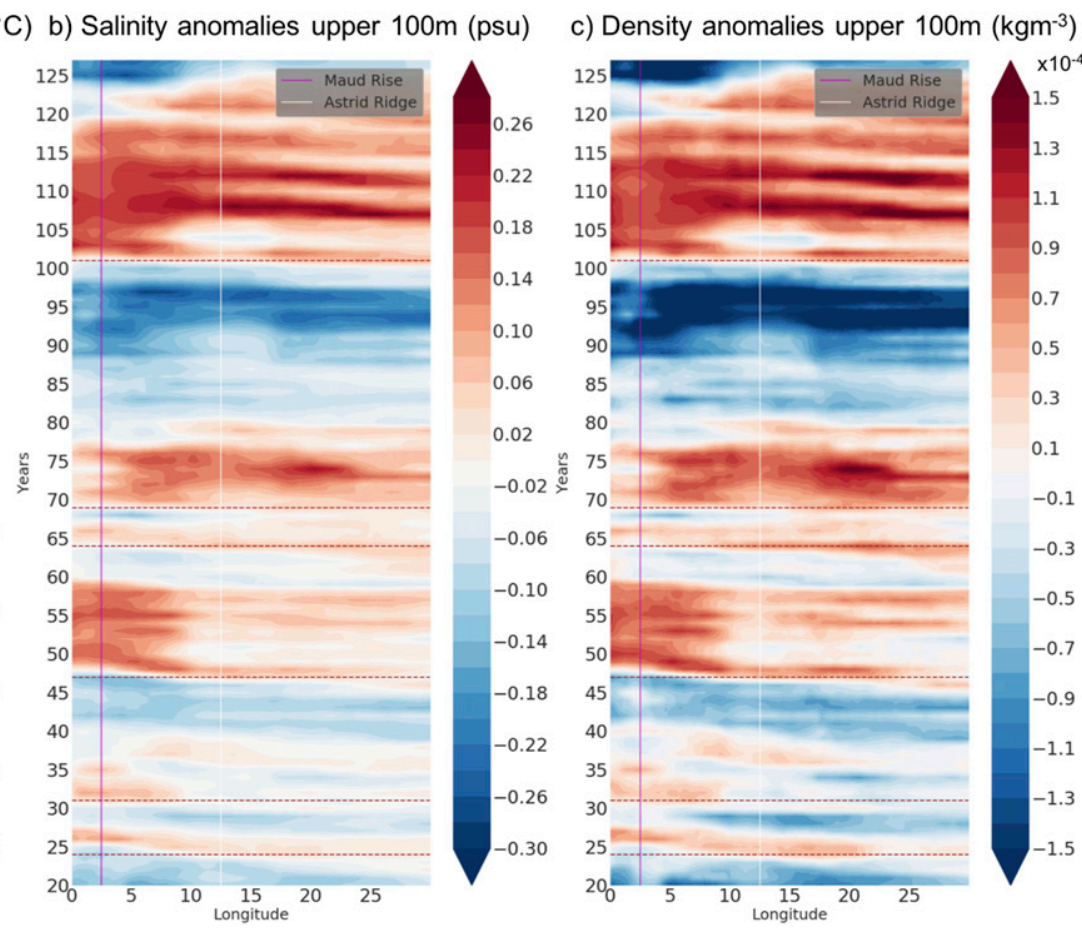

FIG. 13. As in Fig. 12, but for the full length of the E3SMv0-HR simulation. The pink and white lines indicate the central peak of Maud Rise and Astrid Ridge, respectively. The horizontal red dashed lines indicate the MRP-I years.

interaction of the flow with Astrid Ridge. The westward advection of high upper-ocean salinity over Astrid Ridge weakens the upper-ocean stratification by increasing the surface density (Fig. 12c). Furthermore, convection can be triggered by making the upper $100 \mathrm{~m}$ denser than the subsurface layer, especially if the high-salinity anomalies are advected over Taylor caps. As indicated by all six MRPs, we can make the case that the highsalinity anomalies trigger MRPs when they advect over the Taylor cap region around Maud Rise and Astrid Ridge.

If high surface-salinity anomalies can trigger MRPs, then the null hypothesis, that is, that MRP-N years do not coincide with high surface-salinity anomalies, should also be verified. Figure 13 is identical to Fig. 12, except that it presents the upper water-mass anomalies spanning the entire period of the E3SMv0-HR simulation. This readily shows that all MRP-N years feature exclusively zero or negative salinity anomalies upstream of Maud Rise and Astrid Ridge. Negative salinity anomalies at the surface enhance stratification thus hindering convection and MRP formation.

\section{e. Effect of MRPs on deep water masses}

The WDW is the only source of subsurface heat in the Weddell Sea for the region around Maud Rise. The heat content of the WDW is also an important factor for long-lasting polynyas (Martin et al. 2013; Cheon et al. 2015). The only pathway for the WDW to enter the Maud Rise region is through the eastern limb of the Weddell Gyre where the gyre separates from the ACC (Foster and Carmack 1976; Schröder and Fahrbach 1999).

During the discussion of Figs. 8 and 12, we described the effects of convection around Maud Rise on WDW and upper-ocean water-mass properties. To relate this to the heat reservoir at depth, we next examine the evolution of the water-mass properties over time and depth in the region around Maud Rise $\left(64^{\circ}-68^{\circ} \mathrm{S}, 0^{\circ}-20^{\circ} \mathrm{E}\right)$ throughout the simulation in terms of temperature and salinity anomalies (Fig. 14). In the years preceding MRP-I years, we find a pronounced positive temperature anomaly at depth (between 150 and 1500 m; Fig. 14a), indicating anomalously warm water. The core of the warm anomaly is located at $300-600-\mathrm{m}$ depth, which corresponds to the WDW core. Once an MRP is triggered, starting in the austral winter of the MRP-I year, we see an abrupt decline in the WDW temperature. This indicates deep convection and mixing of the cold ASW with the warm subsurface WDW, creating a positive temperature anomaly in the upper $150 \mathrm{~m}$ and a negative temperature anomaly underneath. During subsequent MRP years, the negative temperature anomaly spreads gradually down to $3000 \mathrm{~m}$, apparently affecting deep and bottom water 
a) Temperature anomaly $\left({ }^{\circ} \mathrm{C}\right)$ averaged over $64^{\circ} \mathrm{S}-68^{\circ} \mathrm{S} ; 0^{\circ} \mathrm{E}-20^{\circ} \mathrm{E}$.

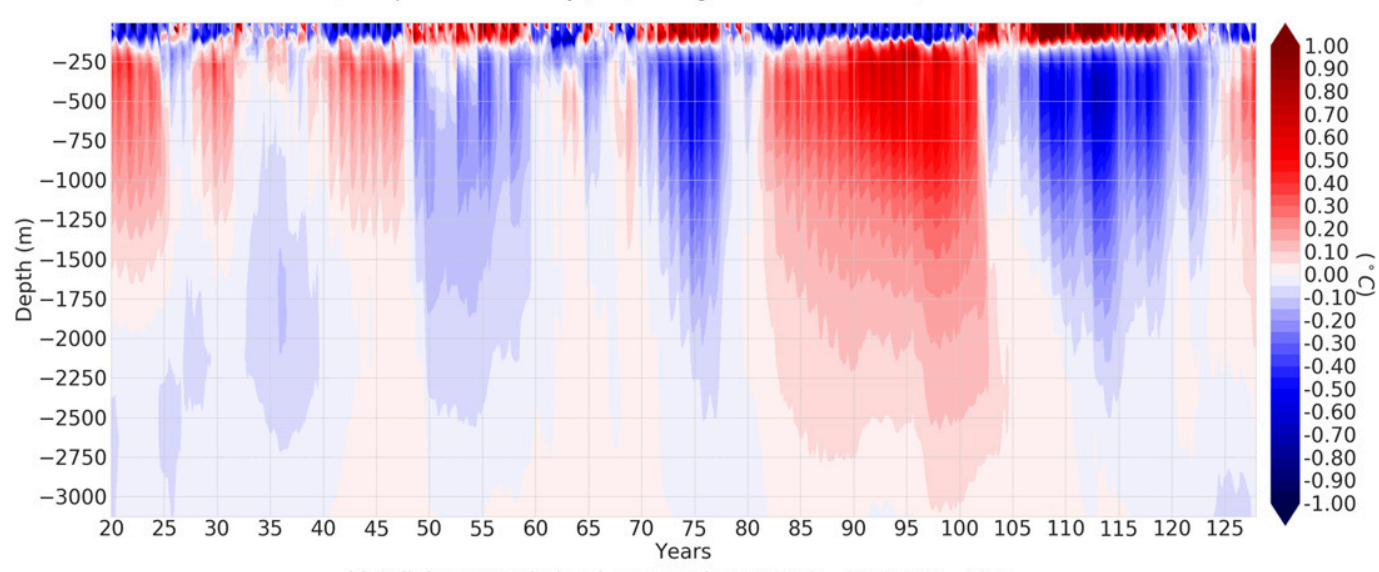

b) Salinity anomaly (psu) averaged over $64^{\circ} \mathrm{S}-68^{\circ} \mathrm{S} ; 0^{\circ} \mathrm{E}-20^{\circ} \mathrm{E}$.

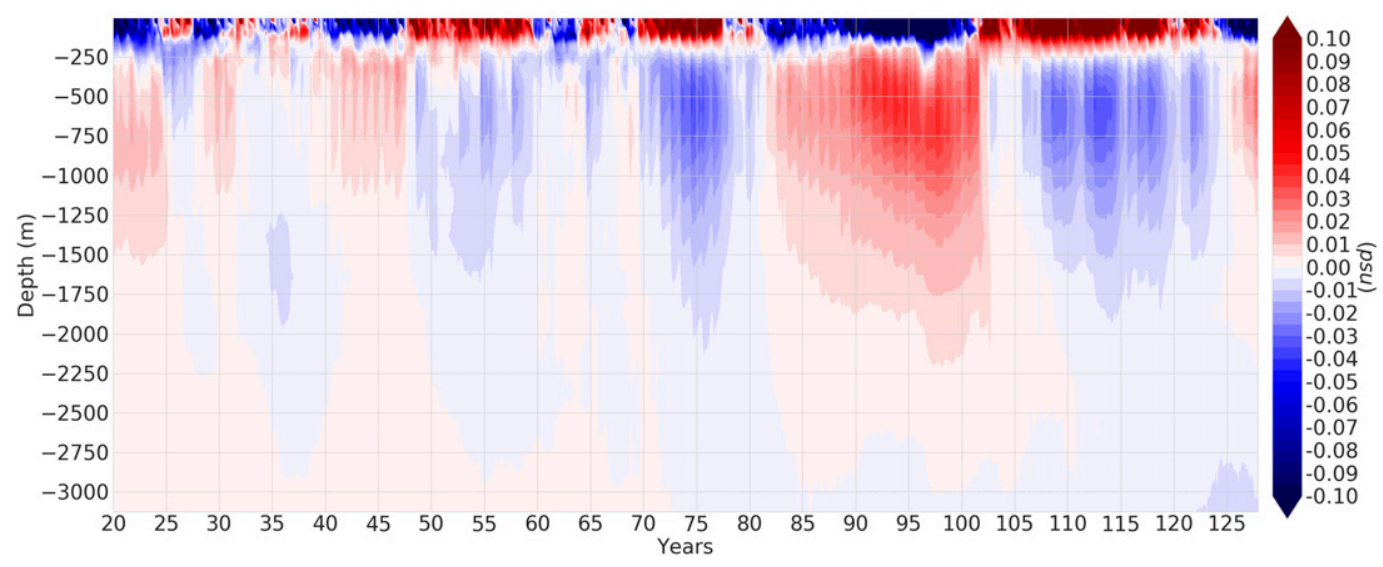

FIG. 14. Time series of (a) potential temperature and (b) salinity anomaly profiles averaged over the area $64^{\circ}-$ $68^{\circ} \mathrm{S}, 0^{\circ}-20^{\circ} \mathrm{E}$ for the full simulation period. The anomalies are computed relative to the mean monthly climatology over years $20-127$.

(WSDW, WSBW) properties. Cooling of the WDW layer has a significant impact on the Southern Ocean as previously reported in observational studies (e.g., Gordon 1978, 1981).

\section{Summary and conclusions}

Observations in the 1970s, previous modeling studies, and our E3SMv0-HR simulation indicate that MRPs act as a precursor to WSPs (Gordon 1978; Martinson et al. 1981; Holland 2001; Dufour et al. 2017). The development of WSPs in the E3SMv0-HR simulation will be the subject of a follow-up paper. Here we focused on the preconditioning and formation of MRPs. These are governed by bathymetric effects and thus are highly dependent on model resolution. Our study can be viewed as being complementary to the recent study by Dufour et al. (2017) who focused on the formation of WSPs in a high-resolution ESM simulation. Our key findings are summarized as follows:
1) The upper $100-\mathrm{m}$ salinity structure near Maud Rise and Astrid Ridge is an important factor for triggering MRPs. All of the simulated MRPs are preceded by high upper-ocean salinity anomalies upstream of the Maud Rise-Astrid Ridge complex. These anomalies start propagating about 1-2 years prior to an MRP event, in some cases from the eastern limb of the Weddell Gyre $\left(30^{\circ} \mathrm{E}\right)$, and in other cases from the region east of Astrid Ridge $\left(20^{\circ}-25^{\circ} \mathrm{E}\right)$. Since the flow in the vicinity of Maud Rise is governed by a semipermanent Taylor cap, the salinity anomalies propagate along the northern flank of Maud Rise rather than over it. The northern flank is characterized by a crescent of large positive relative vorticity of ocean currents and sea ice drift, slightly lower sea ice concentration, a shallow mixed layer, warmer and saltier water at depth (WDW), and slightly warmer water at the surface, all relative to its surrounding. The presence of the Taylor cap over the Maud RiseAstrid Ridge complex preconditions the region with 
low stratification which, when combined with highsalinity anomalies in the upper layer, triggers convection. Once convection has set in, a positive feedback ensues, bringing a reservoir of warmer and saltier WDW to the surface, which, upon cooling, enhances convection, eventually destabilizing the whole region over and around Maud Rise and Astrid Ridge to the point that an MRP emerges. In this process, the first sign of destabilization and polynya formation appears mostly over the peak of Astrid Ridge, if not east of Astrid Ridge.

2) High model resolution is essential for bottom topography to become steep and high enough to produce a realistically tall Taylor cap and for resolving the detailed circulation around Maud Rise and Astrid Ridge. Figure 2 illustrates the difference between the state-of-the-art measured General Bathymetric Chart of the Oceans (GEBCO) bathymetry and that used in E3SMv0-HR and E3SMv0-LR. It can be readily seen that the high-resolution bathymetry matches the measured one substantially better than the one used for the low-resolution model. The crest of Maud Rise in the E3SMv0-LR bathymetry is at most $2200 \mathrm{~m}$ below the surface, while that of E3SMv0-HR reaches $1600 \mathrm{~m}$, which corresponds almost with the Maud Rise peak in the GEBCO bathymetry. The standard $1^{\circ}$ E3SMv0-LR simulation does not produce any open-ocean polynya during its entire duration (200 years). Favorable conditions for Taylor columns to emerge and interact with the surface depend on the steepness and height of a seamount above the sea floor and on the ambient stratification (Chapman and Haidvogel 1992). In the Southern Ocean, Maud Rise has the largest potential for Taylor columns to occur (Meredith et al. 2015). An underrepresented steepness and height of Maud Rise in the model bathymetry prevents the formation of sufficiently strong Taylor columns to form. Findings 1 and 2 together explain the necessary conditions for MRPs to form and the MRP formation process itself, all on the basis of detailed physical processes that evolved in the fully coupled E3SMv0HR simulation.

3) The simulated halo of a shallow mixed layer, warm and salty WDW, as well as low sea ice concentration during MRP-N years closely matches results based on oceanographic measurements and satellite remote sensing (e.g., de Steur et al. 2007; Lindsay et al. 2008). The presence of the halo of lower ice concentration is associated with a shoaling of the thermocline that allows for sufficient entrainment of WDW to the upper ocean to prevent a $100 \%$ sea ice coverage as found in the surrounding waters. This

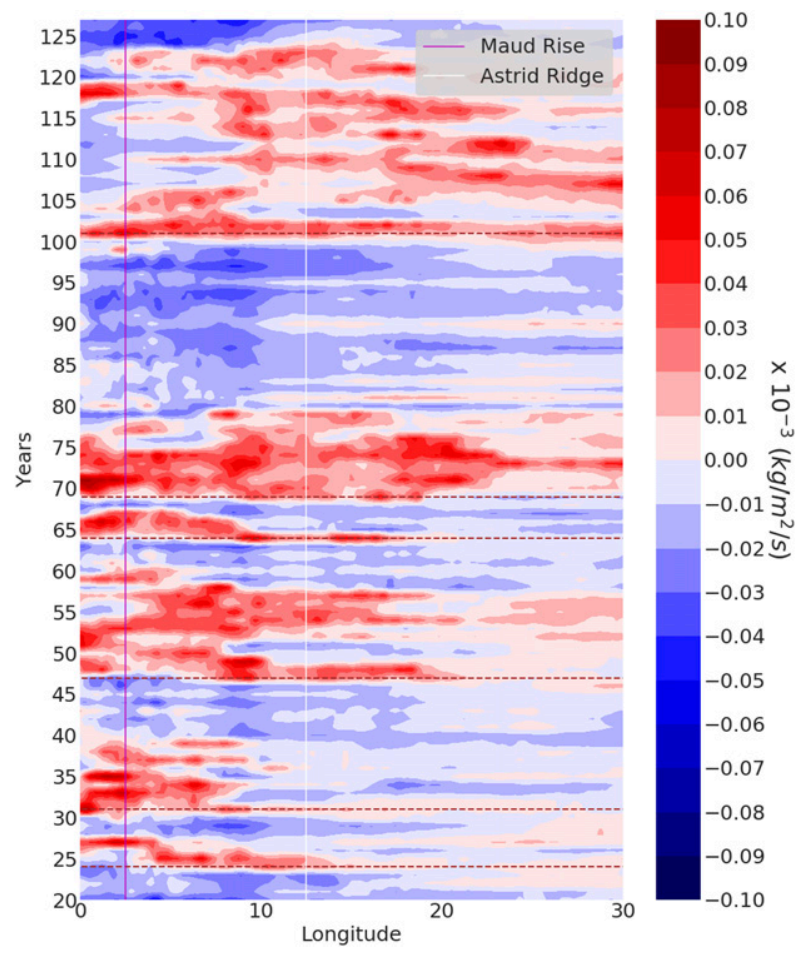

FIG. 15. As in Fig. 13, but for the JASO mean surface freshwater flux anomalies. The anomalies are computed relative to the mean monthly climatology over years 20-127. The pink and white lines indicate the central peak of Maud Rise and Astrid Ridge, respectively. The horizontal red dashed lines indicate the MRP-I years.

feature is seen frequently during nonpolynya years in satellite observations. The halo is also proof of a permanent Taylor cap over Maud Rise and that this Taylor cap is simply stronger during polynya years (the strength of the Taylor cap is determined by its proximity to the surface mixed layer).

4) The intensification of the Weddell Gyre seems to play a minor role for the transition from MRP-P to MRP-I years but seems more relevant for the maintenance of WSPs and large ice-free embayments in association with a sustained negative wind stress curl anomaly, a subject to be scrutinized in a follow-up study.

5) The heat content of WDW plays an important role in sustaining polynyas. Prior to MRP years, we see an accumulation of WDW heat and salt content around Maud Rise. On the other hand, MRPs reoccurring over a number of consecutive years can impact deep water formation.

A Hovmöller diagram similar to that of Fig. 14 but for the JASO averaged surface freshwater flux anomalies (Fig. 15) shows that in all MRP-I cases, the Maud Rise region transitions from relatively dry to relatively wet atmospheric conditions when going from MRP-P to 
MRP-I. Comparing these results with Fig. 13a, however, reveals a direct correspondence between freshwater flux and upper-ocean salinity and temperature, indicating that the freshwater flux anomalies are mainly caused by warm surface temperature anomalies. Additional comparison with Fig. $4 \mathrm{~b}$ indicates that these are mainly caused by low ice concentration anomalies in association with the MRPs. In our simulation, precipitation anomalies are thus not a cause for MRPs, but rather a result of them, as also found in Weijer et al. (2017). A question that arises is what causes the high-salinity anomalies (Fig. 12b) in Fig. 12, either locally or east of the Maud Rise-Astrid Ridge complex, before they are advected westward. We will investigate this more deeply in our subsequent paper on WSPs.

Although we have not considered eddy effects (Stössel et al. 2015) in this paper, it is likely that the ability of a model to produce eddies is important for MRPs to form. Part of the flow impinging on Maud Rise circulates anticyclonically around its northern flank, as expected from conservation of potential vorticity. During this process, cyclonic and anticyclonic eddies are generated (e.g., Holland 2001). Some of these mesoscale eddies flow downstream, while most of them linger near the seamount, in particular along its eastern flank. There is a weak cyclonic inner circulation over Maud Rise that is intensified along its northern flank, which has also been reported by observations (Gordon and Huber 1990). Anomalous currents in the region where the Weddell Gyre separates from the ACC could also play a role in MRP formation because of the large mesoscale eddies that are usually present in this region and of the possible impact that these eddies may have on horizontal heat and salt transport toward Maud Rise (Orsi et al. 1995). A preliminary inspection of the sea surface height anomaly during the months of May and June for two specific MRP-I and MRP-N years (not shown) indicates that there is not a clear distinction between MRP-I and MRP-N years in terms of eddy generation and propagation toward Maud Rise and Astrid Ridge. Therefore, more systematic and quantitative studies are necessary to investigate the possible impact of eddies on MRP formation, which are beyond the scope of this paper.

The 130-yr-long E3SMv0-HR simulation analyzed here reveals 40 years with open-ocean polynyas in the greater Weddell Sea. According to Gordon (2014), deep convection in the Weddell Sea was more active in the past and has weakened because of increased freshwater input in the upper ocean related to recent climate change, leading to increased stratification. The study of de Lavergne et al. (2014) addresses the importance of ESMs being capable of producing open-ocean polynyas under preindustrial conditions. They analyzed a series of CMIP5 ESMs, all of which are low-resolution models.
They stressed that there are two classes of CMIP5 models: convecting and nonconvecting ones. Low-resolution CESM models (and with that E3SMv0-LR) are of the latter type. They concluded that convecting ESMs are capable of simulating the transition from a convective to a nonconvective state with increasing greenhouse gases, while nonconvecting ESMs are not. Our study and that of Dufour et al. (2017) demonstrate that highresolution ESM simulations with preindustrial $\mathrm{CO}_{2}$ concentration levels are able to reproduce WSPs. The fact that CESM, and thus E3SMv0, becomes a convecting ESM upon switching from low to high resolution suggests that E3SMv0-HR will most likely also be able to realistically simulate the transition to a nonconvective state with anthropogenic forcing. The crucial difference to the convecting low-resolution ESM simulations is that in E3SMv0-HR convection emerges for the right physical reason, namely, as a result of sufficiently resolved bathymetry that leads to the intermittent occurrence of MRPs, which in turn is a necessary condition for WSPs to form. In an upcoming paper, we will study the mechanisms behind the westward expansion of MRPs into WSPs, and the possible impact of WSPs on Antarctic Bottom Water formation.

Acknowledgments. P. Kurtakoti and M. Veneziani acknowledge support of the U.S. Department of Energy (DOE)'s Office of Science (BER) through the E3SM project and the Center for Space and Earth Science (CSES) at the Los Alamos National Laboratory through a 2-yr graduate student project. Kurtakoti was also supported by the Department of Oceanography at Texas A\&M University. A. Stössel acknowledges support from the CSES project for associated visits at LANL. W. Weijer acknowledges support from the DOE BER's RGMA program as a contribution to the HiLAT project. The authors are also thankful for Mat Maltrud and Elizabeth Hunke's support in providing guidance on the POP and CICE model fields whenever necessary. Los Alamos National Laboratory is operated by Los Alamos National Security, LLC, for the National Nuclear Security Administration of the U.S. Department of Energy under Contract DE-AC52-06NA25396.

\section{REFERENCES}

Alverson, K., and W. B. Owens, 1996: Topographic preconditioning of open-ocean deep convection. J. Phys. Oceanogr., 26, 2196-2213, https://doi.org/10.1175/1520-0485(1996)026<2196: TPOOOD $>2.0 . C O ; 2$.

Beckmann, A., R. Timmermann, A. F. Pereira, and C. Mohn, 2001: The effect of flow at Maud Rise on the sea-ice coverNumerical experiments. Ocean Dyn., 52, 11-25, https:/doi.org/ 10.1007/s10236-001-8173-5. 
Bergh, H. W., 1987: Underlying fracture zone nature of Astrid Ridge off Antarctica's Queen Maud Land. J. Geophys. Res., 92, 475-484, https://doi.org/10.1029/JB092iB01p00475.

Bersch, M., G. A. Becker, H. Frey, and K. P. Koltermann, 1992: Topographic effects of the Maud Rise on the stratification and circulation of the Weddell Gyre. Deep-Sea Res., 39A, 303-331, https://doi.org/10.1016/0198-0149(92)90111-6.

Chapman, D. C., and D. B. Haidvogel, 1992: Formation of Taylor caps over a tall isolated seamount in a stratified ocean. Geophys. Astrophys. Fluid Dyn., 64, 31-65, https://doi.org/10.1080/ 03091929208228084.

Cheon, W. G., Y.-G. Park, J. R. Toggweiler, and S.-K. Lee, 2014: The relationship of Weddell Polynya and open-ocean deep convection to the Southern Hemisphere westerlies. J. Phys. Oceanogr., 44, 694-713, https://doi.org/10.1175/JPO-D-13-0112.1.

—, S.-K. Lee, A. L. Gordon, Y. Liu, C.-B. Cho, and J. J. Park, 2015: Replicating the 1970's Weddell Polynya using a coupled oceansea ice model with reanalysis surface flux fields. Geophys. Res. Lett., 42, 5411-5418, https://doi.org/10.1002/2015GL064364.

Deacon, G. R. E., 1963: The Southern Ocean. The Composition of Sea-Water and Comparative and Descriptive Oceanography, M. N. Hill, Ed., The Sea-Ideas and Observations on Progress in the Study of the Seas, Vol. 2, John Wiley and Sons, 281296 pp.

de Lavergne, C., J. B. Palter, E. D. Galbraith, R. Bernardello, and I. Marinov, 2014: Cessation of deep convection in the open Southern Ocean under anthropogenic climate change: Supplementary information. Nat. Climate Change, 4, 278-282, https://doi.org/10.1038/nclimate2132.

Dennis, J. M., and Coauthors, 2012: CAM-SE: A scalable spectral element dynamical core for the Community Atmosphere Model. Int. J. High Perform. Comput. Appl., 26, 74-89, https:// doi.org/10.1177/1094342011428142.

de Steur, L., D. M. Holland, R. D. Muench, and M. G. McPhee, 2007: The warm-water "halo" around Maud Rise: Properties, dynamics and impact. Deep-Sea Res. I, 54, 871-896, https:// doi.org/10.1016/j.dsr.2007.03.009.

Dufour, C. O., A. K. Morrison, S. M. Griffies, I. Frenger, H. Zanowski, and M. Winton, 2017: Preconditioning of the Weddell Sea polynya by the ocean mesoscale and dense water overflows. J. Climate, $\mathbf{3 0}$, 7719-7737, https://doi.org/10.1175/JCLI-D-16-0586.1.

Foster, T. D., and E. C. Carmack, 1976: Frontal zone mixing and Antarctic Bottom Water formation in the southern Weddell Sea. Deep-Sea Res. Oceanogr. Abstr., 23, 301-317, https:// doi.org/10.1016/0011-7471(76)90872-X.

Gordon, A. L., 1978: Deep Antarctic convection west of Maud Rise. J. Phys. Oceanogr., 8, 600-612, https://doi.org/10.1175/ 1520-0485(1978)008<0600:DACWOM > 2.0.CO;2.

_ 1981: Weddell Deep Water: Source and variability. Antarct. J. U.S., 16, 99-100.

— 1982: Weddell Deep Water variability. J. Mar. Res., 40, 199-217.

_ 2014: Southern Ocean polynya. Nat. Climate Change, 4, 249 250, https://doi.org/10.1038/nclimate2179.

— J. Geophys. Res., 95, 11 655-11 672, https://doi.org/10.1029/ JC095iC07p11655.

—, M. Visbeck, and J. C. Comiso, 2007: A possible link between the Weddell Polynya and the southern annular mode J. Climate, 20, 2558-2571, https://doi.org/10.1175/JCLI4046.1.

Hirabara, M., H. Tsujino, H. Nakano, and G. Yamanaka, 2012: Formation mechanism of the Weddell Sea polynya and the impact on the global abyssal ocean. J. Oceanogr., 68, 771-796, https://doi.org/ 10.1007/s10872-012-0139-3.
Hogg, N. G., 1973: On the stratified Taylor column. J. Fluid Mech., 58, 517-537, https://doi.org/10.1017/S0022112073002302.

Holland, D. M., 2001: Explaining the Weddell Polynya-A large ocean eddy shed at Maud Rise. Science, 292, 1697-1700, https:// doi.org/10.1126/science.1059322.

Hunke, E. C., and W. H. Lipscomb, 2010: CICE: The Los Alamos Sea Ice Model documentation and software user's manual, version 4.1. Doc. LA-CC-06-012, 76 pp., http://csdms.colorado.edu/w/images/ CICE_documentation_and_software_user's_manual.pdf.

Hurrell, J. W., and Coauthors, 2013: The Community Earth System Model: A framework for collaborative research. Bull. Amer. Meteor. Soc., 94, 1339-1360, https://doi.org/10.1175/ BAMS-D-12-00121.1.

Large, W. G., J. C. Mcwilliams, and S. C. Doney, 1994: Oceanic vertical mixing - A review and a model with a nonlocal boundary layer parameterization. Rev. Geophys., 32, 363-403, https:// doi.org/10.1029/94RG01872.

Lawrence, D. M., and Coauthors, 2011: Parameterization improvements and functional and structural advances in version 4 of the Community Land Model. J. Adv. Model. Earth Syst., 3, M03001, https://doi.org/10.1029/2011MS00045.

Lindsay, R. W., D. M. Holland, and R. A. Woodgate, 2004: Halo of low ice concentration observed over the Maud Rise seamount. Geophys. Res. Lett., 31, L13302, https://doi.org/ 10.1029/2004GL019831.

-, R. Kwok, L. de Steur, and W. Meier, 2008: Halo of ice deformation observed over the Maud Rise seamount. Geophys. Res. Lett., 35, L15501, https://doi.org/10.1029/2008GL034629.

Martin, T., W. Park, and M. Latif, 2013: Multi-centennial variability controlled by Southern Ocean convection in the Kiel Climate Model. Climate Dyn., 40, 2005-2011, https://doi.org/ 10.1007/s00382-012-1586-7.

Martinson, D. G., 1990: Evolution of the Southern Ocean winter mixed layer and sea ice: Open ocean deep water formation and ventilation. J. Geophys. Res., 95, 11 641-11 654, https://doi.org/ 10.1029/JC095iC07p11641.

_ P. D. Killworth, and A. L. Gordon, 1981: A convective model for the Weddell Polynya. J. Phys. Oceanogr., 11, 466-488, https://doi.org/ 10.1175/1520-0485(1981)011<0466:ACMFTW>2.0.CO;2.

Maslanik, J. and J. Stroeve, 1999: Near-real-time DMSP SSMIS daily polar gridded sea ice concentrations, updated daily, version 1 . NASA National Snow and Ice Data Center, accessed 15 November 2017, https://doi.org/10.5067/U8C09DWVX9LM.

Meredith, M. P., A. S. Meijers, A. C. N. Garabato, P. J. Brown, H. J. Venables, E. P. Abrahamsen, L. Jullion, and M.-J. Messias, 2015: Circulation, retention, and mixing of waters within the WeddellScotia Confluence, Southern Ocean: The role of stratified Taylor columns. J. Geophys. Res. Oceans, 120, 547-562, https://oi.org/ 10.1002/2014JC010462.

Morales Maqueda, M. A., A. J. Willmott, and N. R. T. Biggs, 2004: Polynya dynamics: A review of observations and modeling. Rev. Geophys., 42, RG1004, https://doi.org/10.1029/ 2002RG000116.

Mory, M., M. E. Stern, and R. W. Griffiths, 1987: Coherent baroclinic eddies on a sloping bottom. J. Fluid Mech., 183, 45-62, https://doi.org/ 10.1017/S0022112087002519.

Orsi, A. H., W. D. Nowlin Jr., and T. Whitworth III, 1993: On the circulation and stratification of the Weddell Gyre. Deep-Sea Res. I, 40, 169-203, https://doi.org/10.1016/0967-0637(93)90060-G. , T. Whitworth III, and W. D. Nowlin Jr., 1995: On the meridional extent and fronts of the Antarctic Circumpolar Current. Deep-Sea Res. I, 42, 641-673, https://doi.org/10.1016/ 0967-0637(95)00021-W. 
Ou, H. W., 1991: Some effects of a seamount on oceanic flows. J. Phys. Oceanogr., 21, 1835-1845, https://doi.org/10.1175/ 1520-0485(1991)021<1835:SEOASO > 2.0.CO;2.

Proudman, J., 1916: On the motion of solids in a liquid possessing vorticity. Proc. Roy. Soc. London, 92A, 408-424, https://doi. org/10.1098/rspa.1916.0026.

Schröder, M., and E. Fahrbach, 1999: On the structure and the transport of the eastern Weddell Gyre. Deep-Sea Res. II, 46, 501-527, https://doi.org/10.1016/S0967-0645 (98)00112-X.

Small, R. J., and Coauthors, 2014: A new synoptic scale resolving global climate simulation using the Community Earth System Model. J. Adv. Model. Earth Syst., 6, 1065-1094, https:// doi.org/10.1002/2014MS000363.

Smith, R., and Coauthors, 2010: The Parallel Ocean Program (POP) reference manual: Ocean component of the Community Climate System Model (CCSM). Los Alamos National Laboratory Tech. Rep. LAUR-10-01853, 141 pp., http://www.cesm.ucar.edu/models/cesm1.0/pop2/doc/sci/ POPRefManual.pdf.
Stössel, A., and S.-J. Kim, 2001: Decadal deep-water variability in the subtropical Atlantic and convection in the Weddell Sea.J. Geophys. Res., 106, 22 425-22 440, https://doi.org/10.1029/2000JC000335.

- D. Notz, F. A. Haumann, H. Haak, J. Jungclaus, and U. Mikolajewicz, 2015: Controlling high-latitude Southern Ocean convection in climate models. Ocean Modell., 86, 5875, https://doi.org/10.1016/j.ocemod.2014.11.008.

Taylor, G. I., 1923: Experiments on the motion of solid bodies in rotating fluids. Proc. Roy. Soc. London, 104A, 213-218, https://doi.org/10.1098/rspa.1923.0103.

Weijer, W., M. Veneziani, A. Stössel, M. W. Hecht, N. Jeffery, A. Jonko, T. Hodos, and H. Wang, 2017: Local atmospheric response to an open-ocean polynya in a high-resolution climate model. J. Climate, 30, 1629-1641, https://doi.org/10.1175/ JCLI-D-16-0120.1.

Zwally, H. J., J. C. Comiso, C. L. Parkinson, W. J. Campbell, F. D. Carsey, and P. Gloersen, 1983: Antarctic sea ice, 1973-1976: Satellite passive-microwave observations. NASA Tech. Rep. NASA-SP-459, 222 pp., https://ntrs.nasa.gov/archive/ nasa/casi.ntrs.nasa.gov/19840002650.pdf. 